\title{
Landing Gear Noise Prediction and Analysis for Tube-And- Wing and Hybrid-Wing-Body Aircraft
}

\author{
Yueping Guo* \\ NEAT Consulting, Seal Beach, CA 90740 USA \\ and \\ Casey L. Burley ${ }^{\dagger}$ and Russell H. Thomas* \\ NASA Langley Research Center, Hampton, VA 23681 USA
}

\begin{abstract}
Improvements and extensions to landing gear noise prediction methods are developed. New features include installation effects such as reflection from the aircraft, gear truck angle effect, local flow calculation at the landing gear locations, gear size effect, and directivity for various gear designs. These new features have not only significantly improved the accuracy and robustness of the prediction tools, but also have enabled applications to unconventional aircraft designs and installations. Systematic validations of the improved prediction capability are then presented, including parametric validations in functional trends as well as validations in absolute amplitudes, covering a wide variety of landing gear designs, sizes, and testing conditions. The new method is then applied to selected concept aircraft configurations in the portfolio of the NASA Environmentally Responsible Aviation Project envisioned for the timeframe of 2025. The landing gear noise levels are on the order of 2 to 4 $\mathrm{dB}$ higher than previously reported predictions due to increased fidelity in accounting for installation effects and gear design details. With the new method, it is now possible to reveal and assess the unique noise characteristics of landing gear systems for each type of aircraft. To address the inevitable uncertainties in predictions of landing gear noise models for future aircraft, an uncertainty analysis is given, using the method of Monte Carlo simulation. The standard deviation of the uncertainty in predicting the absolute level of landing gear noise is quantified and determined to be 1.4 EPNL dB.
\end{abstract}

$\begin{array}{ll}d B & =\text { decibel } \\ M & =\text { local Mach number } \\ M_{0} & =\text { freestream Mach number } \\ \alpha & =\text { angle of attack } \\ \gamma & =\text { gear truck angle } \\ \theta & =\text { polar angle } \\ \phi & =\text { azimuthal angle }\end{array}$

\section{Nomenclature}

\section{Introduction}

Aircraft landing gears are known to be a major noise source at approach conditions, and the prediction of landing gear noise [Refs 1-8] and its reduction [Refs 9-14] have been active research topics for many years. Due to the intricate geometry of landing gear designs and the complex flow conditions, landing gear noise prediction for practical aircraft applications has entirely relied on empirical approaches and physics-based modeling, the latter aiming to capture and model individual flow features that dominantly affect the noise generation process. This

\footnotetext{
* NEAT Consulting, 3830 Daisy Circle, Seal Beach, CA 90740, AIAA Associate Fellow

$\dagger$ Senior Research Engineer, Aeroacoustics Branch, MS 461, AIAA Senior Member

* Senior Research Engineer, Aeroacoustics Branch, MS 461, AIAA Senior Member
} 
approach has seen significant success in recent years [e.g. Refs 1-5], and the methodologies developed in these efforts can be expected to serve the purpose of landing gear noise prediction for the foreseeable future. These methodologies, however, still contain incomplete features and have potential for improvements, examples of which are clearly identified in Ref 6 . Furthermore, since the original prediction methodologies are developed for conventional Tube-And-Wing $(\mathrm{T}+\mathrm{W})$ aircraft, new features may appear on unconventional aircraft configurations such as Hybrid-Wing-Body (HWB) aircraft, which may have significant effects on landing gear noise. The work reported in this paper represents a step in that direction; the prediction methodologies developed in Refs 3-5 are improved for better accuracy and robustness, and are extended for applications to unconventional aircraft.

The new landing gear noise prediction method presented in this paper offers several improvements over previous models. Among the most significant is the inclusion of improved installation effects. Due to model fidelity and flow Reynolds number effects, landing gear noise tests require full configuration models [Refs 15-18], which makes most wind tunnel tests possible only for single isolated gears without any installation effects. Thus, prediction schemes developed based on wind tunnel test data for isolated gears need separate models for the installation effects including the local flow around the landing gear, reflection by the aircraft, and the interaction of the gear wake and the flaps. The local flow velocity approaching the landing gear is an important parameter because it controls the noise level, following the sixth power law. The flow velocity in front of the landing gear was calculated in previous methods [Refs 3-5] by a model derived from numerical data for $\mathrm{T}+\mathrm{W}$ aircraft. This capability is extended in the present model for HWB aircraft by conducting numerical simulations of the HWB aircraft mean flows (Ref 19-21) and extracting a prediction model from the numerical data.

Reflections from the aircraft involve sound propagation and scattering, and thus, can be conveniently handled by standard numerical methods. To be consistent with the goal of quick turn-around aircraft system noise applications, a simple ray tracing method is implemented for the landing gear noise, which enables calculations of aircraft reflections by arbitrary configurations. For conventional $\mathrm{T}+\mathrm{W}$ aircraft, the latter approach improves the reflection model by accounting for deployed flaps and slats. As will be shown, this can cause an increase of the noise in the flyover plane and introduce reflections that are significantly different from those produced by a flat surface. The uniform reflections that are produced by a flat surface result in a noise increase of 3 decibels, and this type of reflection is sometimes used as an approximation in landing gear noise predictions (as was done in the prediction methodology reported in Refs 3-5). The ray-tracing-based reflection model is also applicable to configurations other than conventional $\mathrm{T}+\mathrm{W}$ aircraft and provides a means to compare the reflection effects of different aircraft designs.

Applicability to landing gears of any size is achieved through Strouhal number scaling. The original methods reported in Refs 3-5 use full scale landing gear noise data to model the high frequency noise generated by the small geometric components in the gear assembly. This has limited the applications of the model to full scale aircraft, as reviewed in Ref 6. With consistent Strouhal number modeling, this drawback has been rectified, and the prediction capability can now be applied to landing gears of arbitrary sizes and designs. A practical application of this capability is for small aircraft such as regional jets and general aviation aircraft whose landing gears are small in size and simpler in design, in comparison with large commercial transports.

There are various other improvements, such as the modeling of the effects of gear truck angle and the landing gear noise directivity patterns. Though these improvements will not be discussed in detail individually, their collective effects will be clearly demonstrated by systematic validations involving a large number of test datasets.

The validation cases include various gear sizes, from small models to full scale gears, various designs, from 2wheel to 6-wheel, and various configurations, from isolated gears in wind tunnel tests to full configuration aircraft in flight. As will be shown in this paper, good agreements between predictions and test data are found, both for parametric trends such as spectral shape, Mach number dependence and directivity pattern, as well as for absolute amplitudes, thus demonstrating the accuracy and robustness of the prediction capability.

With the accuracy and robustness of the new prediction capability established, the paper will then discuss its applications to various aircraft in the portfolio of the NASA Environmentally Responsible Aviation (ERA) project. The ERA portfolio includes advanced aircraft concepts that have a 2025 entry into service timeframe and incorporate a full array of 2025 technologies such as lightweight structures, improved high lift systems, and advanced ultrahigh bypass ratio engines. A subset of these aircraft configurations will be studied here for landing gear noise, including a reference aircraft that is representative of current, in service, technology. Even with the same landing gear design, these different aircraft configurations can have different landing gear noise. This will be discussed in detail in this paper. Thus, the differences in landing gear noise between the 2025 ERA aircraft configurations and a reference aircraft (representative of today's aircraft) will be discussed to reveal the functional trends and controlling quantities that most significantly impact the levels of landing gear noise for the currently envisioned 2025 technology ERA aircraft. 
It is recognized that predictions for future aircraft inevitably involve uncertainties, resulting from various causes including imprecise models for the noise-generating flow features and parameters that determine the noise levels. While the uncertainties are difficult to quantify, the method of Monte Carlo simulation provides a means to statistically assess the potential deviations of the predictions, given estimates of the causes for the uncertainties. Such an analysis will be given in this paper for the landing gear noise models. This analysis not only reveals the potential deviations of the predictions, but also points to the directions for potential improvements of the prediction models. Better modeling of the parameters with the top uncertainties can be expected to significantly improve the overall robustness and accuracy of the landing gear noise prediction tool.

\section{Effects of Local Flow}

It is well known that aircraft landing gear noise scales on the sixth power of the incoming flow velocity, and it is well established that the flow velocity for this noise amplitude scaling is the local flow velocity around the installed landing gears. For conventional $\mathrm{T}+\mathrm{W}$ aircraft, models are available for the calculation of the local flow velocity (Ref 5). These models show that the effect of the wing and deployed flaps on the flow is a reduction in velocity of more than 20 percent from the free stream velocity. This is mainly due to the circulation flow around the high lift system, necessary for the production of the lift. It is easy to understand that the local flow can be different for different aircraft configurations, depending on the design of the high lift system. In this section, models of the local flow velocity are described for HWB aircraft, and the flow effects on the landing gear noise are discussed.

The method to develop local flow models for HWB landing gear noise is the same as that for T+W aircraft (Ref 5), namely, use Computational Fluid Dynamics (CFD) to compute the flow fields for various geometric and operational parameters and then extract reduced-order models from the CFD numerical data. The CFD data (discussed in Ref 19) are calculated by a standard CFD method using the OVERFLOW code. The aircraft is a HWB configuration with two engines mounted on the upper surface of the airframe. The details of the aircraft design are given in Refs 19-21. The computation is performed for a semi-span model with 55 million grid points. The aircraft is in a typical landing configuration, with a flight Mach number of 0.2 , the leading edge slats deployed at 30 degrees and the elevons deployed at various angles. The engines are modeled as flow-through. The computations covered a range of values for the aircraft angle of attack, from 2 to 16 degrees, bracketing the expected value of about 12 degrees for HWB landing operations. The model is shown in Figure 1, in which the local regions for the landing gear flow are also illustrated, together with the coordinates of some relevant locations, where $x$ is the flow direction and $y$ is the span direction, as commonly used in CFD computations. As is clear from the rear view (lower diagram in the figure), the main landing gear location is approximately at the junction between the center body and the outer wing. This allows the landing gear systems to be retracted and folded into the center body at cruise conditions, but this unfortunately also leads to an increase in local flow velocity, as will be seen later in the section.

An example of the computed local flow Mach number distributions at the landing gear locations is given in Figure 2 for the case of a mean flow Mach number of 0.2 and an angle of attack of 10 degrees. The contour maps shown in the figure are the two landing gear regions marked $y=0$ and $y=245$ in Figure 1, respectively, for the nose and the main gear. For reference, the gear locations are indicated by the cartoon gears; for the main gear, a 6-wheel cartoon is shown but it does not mean that the main gears of the HWB aircraft will be necessarily of the 6-wheel design.
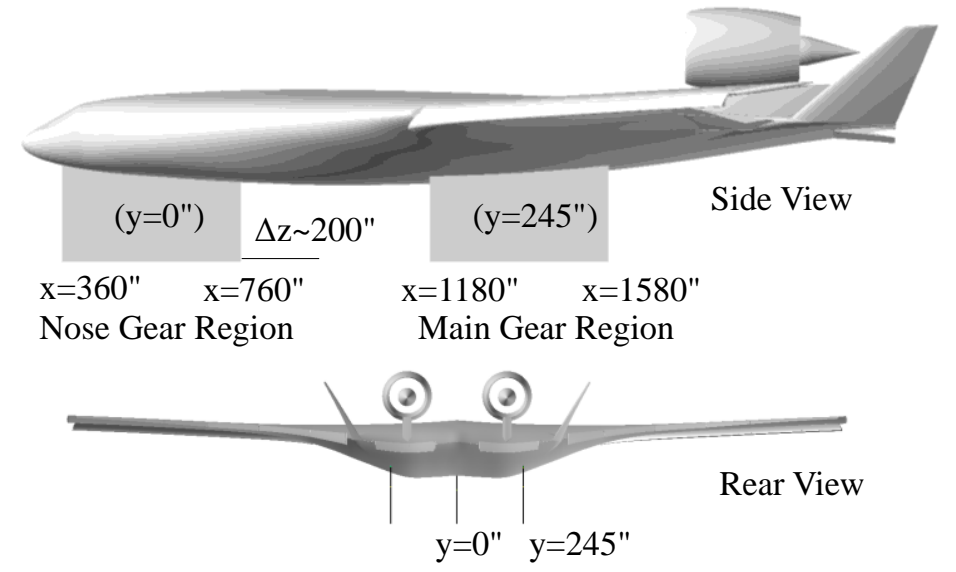

Figure 1. HWB model for CFD computation and the landing gear regions for local flow. 


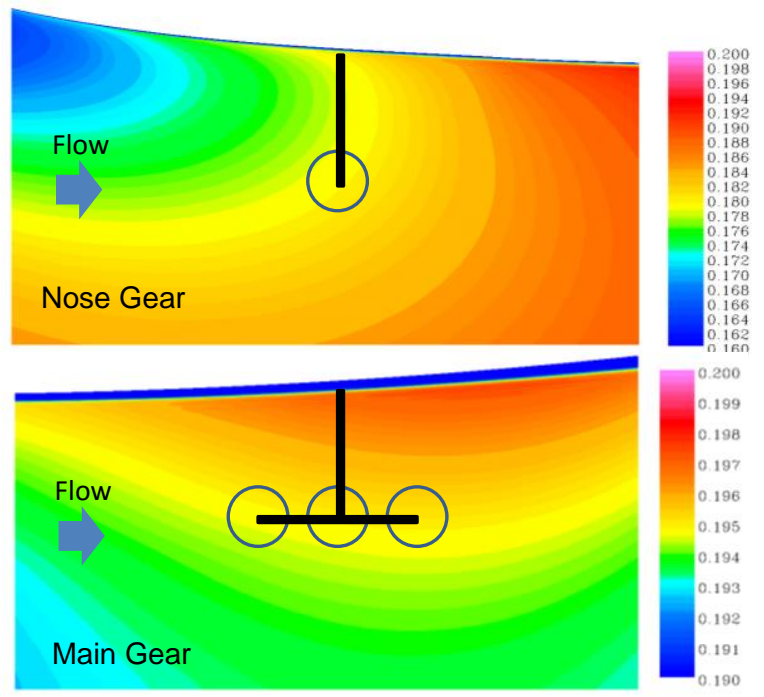

Figure 2. Illustration of Mach number distribution at landing gear locations.

For the main gear, it is seen in Figure 2 that the local flow Mach number is only slightly lower than the free stream Mach number of 0.2. This is in sharp contrast to the case of conventional $\mathrm{T}+\mathrm{W}$ aircraft for which the local flow velocity can be more than 20 percent less than the free stream (Ref 5). Since the landing gear design for HWB aircraft is not expected to be very different from that of conventional aircraft (at least not in the timeframe of 2025), it can be expected that both configurations will have similar landing gear noise sources characteristics, and that the relative noise levels generated by these sources will critically depend on the local flow conditions, of which the incoming flow velocity is one of the dominant parameters. The reduction in flow velocity by more than 20 percent for the conventional $\mathrm{T}+\mathrm{W}$ aircraft leads to a significant reduction in noise levels (about $6 \mathrm{~dB}$ ) compared to the noise radiated by the same landing gear system exposed to a free stream flow. For the HWB aircraft, however, this acoustically beneficial feature is mostly absent, because the local flow Mach number at the main landing gear locations are only slightly lower than the free stream Mach number (as illustrated in Figure 2). This is primarily due to the fact that the landing gears are located at the junction between the center body and the outer wing where the reduction of local flow velocity provided by the lift circulation flow is partially offset by the flow acceleration due to the local geometry changes.

For practical noise predictions (with quick turn-around engineering applications), it is clearly not feasible to use CFD to derive the local flow velocity, especially for parametric studies involving various configurations and flow parameters. Also, full configuration CFD results may not be available in early stages of aircraft product development. It is in fact this difficulty that has motivated the efforts of developing simple models to calculate the local flow velocity for noise prediction. From the analyses of the CFD results, it can be seen that such simple models are indeed feasible. Though the local flow can deviate from the free stream flow, the variations within the local regions are usually gradual and monotonically varying with other parameters. This has been shown to be true also for conventional $\mathrm{T}+\mathrm{W}$ aircraft with both wing-mounted and fuselage-mounted gears. This suggests simple approaches for the model development, using polynomial fitting for the spatial coordinate variations and simple correlations for other parameters. The approach followed here is to analyze the features revealed by the CFD data and extract reduced-order models. Within the parameter domains studied here, the local flow Mach number is a function of free stream Mach number, aircraft angle of attack and spatial coordinates. After analyzing the trends and correlations with these parameters, simple models can be derived in similar form to those given in Ref 5 for conventional $\mathrm{T}+\mathrm{W}$ aircraft, with of course different coefficients for the HWB configuration.

It can be easily argued that the local flow velocities around an aircraft depend on many parameters and that a simple model inevitably involves approximations. It is therefore crucial to check the errors resulting from these approximations to ensure adequate accuracy for the intended use of landing gear noise prediction. To this end, a comparison of the model calculations with CFD data is shown in Figure 3 and Figure 4, respectively for the HWB main and nose landing gears. The figures plot the ratio of the local flow Mach number (denoted by $M$ ) to the free stream Mach number (denoted by $M_{0}$ ) as a function of the distance from the aircraft surface at the gear location. The various symbols in the figure represent the CFD data obtained at various angles of attack, and the curves are the corresponding model predictions. It is seen that the CFD data agree well with the model predictions for most cases. The error between the model predictions and the CFD data is negligible close to the aircraft and in the middle range, 
which is where the landing gear assemblies are located. At large distance from the aircraft surface, at 200 inches, for example, the errors become noticeable, but this is not a concern because landing gears are not likely to be positioned this far away from the airframe.

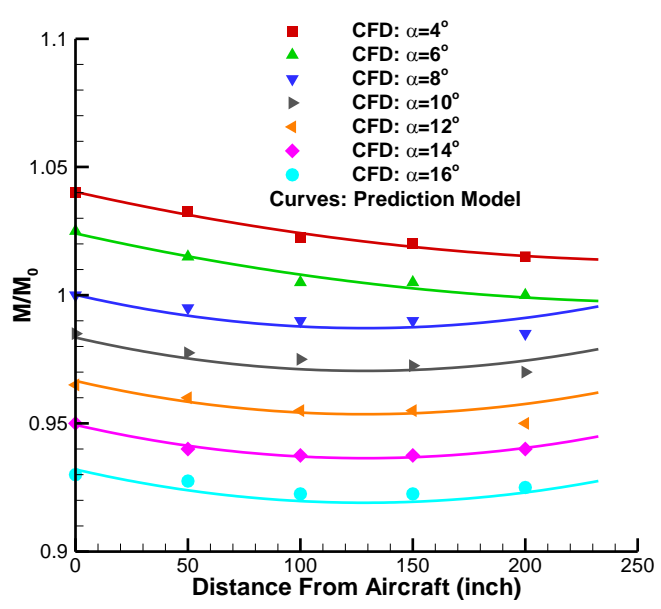

Figure 3. Local Mach number for HWB main gear.

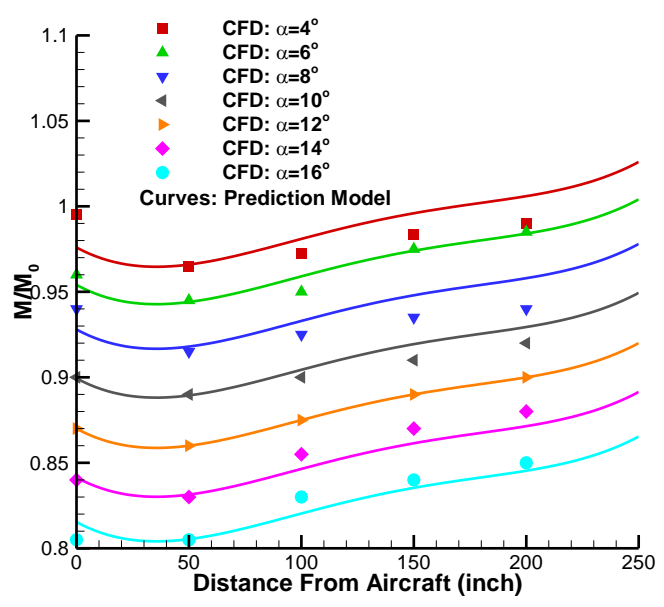

Figure 4. Local Mach number for HWB nose gear.

From Figure 3, it can also be seen that the local Mach number variation is very gradual; at a fixed angle of attack, its variation is about one percent. It is also clear that the local Mach number only slightly deviates from the free stream Mach number. For example, at an angle of attack of 12 degrees, the Mach number ratio is about 0.96, meaning that the local flow velocity is about 4 percent less than the free stream. Similarly, from Figure 4, it is noted that the local flow Mach number for the nose gear does not vary significantly with distance to the aircraft for fixed angles of attack. However, it has a larger deviation from the free stream Mach number. For example, at an angle of attack of 12 degrees, the local flow is about 14 percent slower than the free stream. This is acoustically beneficial, but the nose gear contribution to the total noise is usually small, hence this benefit may not be noticeable in practical applications.

While detailed predictions and discussions for the landing gear noise of various aircraft configurations will be given in a later section, it is instructive to discuss the effects of the flow Mach number on the noise levels according to the scaling law of landing gear noise with flow Mach number. As an order of magnitude estimate, the flight Mach numbers for the HWB aircraft and the conventional T+W aircraft can be taken respectively as 0.2 and 0.25 , which, without considering the installation effects, would yield a noise benefit of about $5.8 \mathrm{~dB}$ for the HWB aircraft. This is based on the sixth power law in Mach number and assumes that the gears for the two cases have the same design. For conventional $\mathrm{T}+\mathrm{W}$ aircraft that have their main landing gear system installed under the wing (such as for the 
Boeing 777 discussed in Ref 5), the local Mach number is about 76 percent of the free stream Mach number, which leads to a local flow Mach number of 0.19. On the other hand, the local Mach number for the HWB landing gears is 0.192 (which is about $96 \%$ of the free stream Mach number at an angle of attack of 12 degrees). Thus, the acoustic benefit of the lower flight Mach number for the HWB aircraft is largely cancelled by the installation effects on the local flow speed (at least in this case). The local flow Mach number, of course, varies with the aircraft angle of attack, as clearly shown in Figure 3. If the HWB aircraft were to fly at smaller angles of attack, the circulation flow would be further reduced, which would in turn further reduce the acoustic benefit. Some results are summarized in Table 1. It is shown in that table that although the HWB aircraft has a much lower flight Mach number than the $\mathrm{T}+\mathrm{W}$ aircraft, the potential acoustic benefit for the landing gear noise due to low flight Mach number is not realized. In fact, the HWB configurations all have slightly higher landing gear noise than the T+W aircraft, though such small differences in noise levels derived from order of magnitude estimates would probably not be noticed in real applications. It is nevertheless important to show the critical role of the installation effects on the local flow velocity that is used to scale the noise amplitude.

Table 1. Acoustic impact of Mach number (negative numbers being noise increase).

\begin{tabular}{l|cccc}
\hline & $T+W$ & $H W B$ & $H W B$ & $H W B$ \\
& $\alpha=6^{o}$ & $\alpha=8^{o}$ & $\alpha=10^{\circ}$ & $\alpha=12^{o}$ \\
\hline Flight Mach Number & 0.25 & 0.2 & 0.2 & 0.2 \\
Local Mach Number & 0.19 & 0.196 & 0.194 & 0.192 \\
\% of Flight Mach Number & 76 & 98 & 97 & 96 \\
Noise Difference (Ref to T+W) & - & $-0.81 \mathrm{~dB}$ & $-0.54 \mathrm{~dB}$ & $-0.27 \mathrm{~dB}$ \\
\hline
\end{tabular}

\section{Effects of Aircraft Reflection}

With landing gear noise sources defined, the effects of reflection from the aircraft surfaces can be accounted for by considering sound propagation and scattering, which are usually modeled separately from the landing gear noise sources. This is necessary because landing gear noise tests require full configurations to maintain model fidelity and realistic flow Reynolds number. Thus, many tests are usually done with full scale and full configuration gears, but without the airframe (Refs 15-18), and prediction models are developed accordingly. Thus, prediction models for isolated gears need to be supplemented by models accounting for the effects of reflection. Having to model the noise radiating from the landing gear and the reflection effects separately actually gives flexibilities in the model's applications. Landing gear designs can be expected to be similar for different aircraft configurations, and thus, the noise prediction for isolated gears can follow the same methodologies. Different aircraft configurations will, of course, have different installation effects, which can then be handled by the separate reflection models.

Since the reflection from the airframe does not involve the source modeling, it can be dealt with by standard numerical methods for sound propagation and scattering. The only difficulty is the requirement for quick turnaround time for practical applications. For full scale and full configuration aircraft at frequencies up to a few kilohertz, not many numerical methods can meet that requirement. The method of ray tracing is probably one of the very few that can, and it is this method that is implemented with the landing gear noise prediction tool discussed here. The theoretical basis of the method is standard and well known (Ref 22), and thus, will not be repeated here. For computation efficiency, it is worth noting that the addition of the reflection capability to the landing gear noise prediction has not induced any noticeable increase in computation time, which remains trivially small, just a few seconds of computing time on an ordinary personal computer. For accuracy, the limitations of ray tracing are well known; it is a high frequency approximation that should be accurate enough in the kilohertz range where the gear components are a few wavelengths away from the airframe.

The effects of airframe reflection on landing gear noise are illustrated in Figure 5. The increase of main landing gear noise due to reflection from a $\mathrm{T}+\mathrm{W}$ aircraft is clearly seen. The noise increase in decibels is plotted as a function of the polar and the azimuthal angles, $\theta$ and $\phi$. The flyover plane is at the azimuthal angle of zero degrees. It is also the plane of symmetry of the airframe and source distribution. The flight direction corresponds to the polar angle of zero degrees while the overhead direction corresponds to a 90 degree polar angle. The aircraft is assumed to have an angle of attack of 6 degrees. The reflection model can deal with a realistic airframe geometry, and the computational effort depends on the complexity of the modeled geometry. To leading order, the geometry is represented by a set of flat panels. Future improvements can be made by refining the geometry, by including features such as the wing dihedral angle and local curvature, for example. The overall pattern in Figure 5 shows that 
the reflection is mostly confined to the polar angular domain ranging from about 30 degrees in the forward quadrant to about 120 degrees in the aft quadrant. Within that domain, the most significant reflection is in the forward quadrant for polar angles less than 90 degrees. This is due to the combined effect of the aircraft angle of attack and the deployed high lift system, namely, the slats and the flaps. This is obviously very different from the uniform reflection of $3 \mathrm{~dB}$ (that would be produced from a large plate) that is sometimes used to approximate aircraft reflection effects; Thus, the high lift system redirects the sound waves to form a non-uniform spatial distribution with zero noise increase at some angles and as high as $6 \mathrm{~dB}$ increase at some other angles.

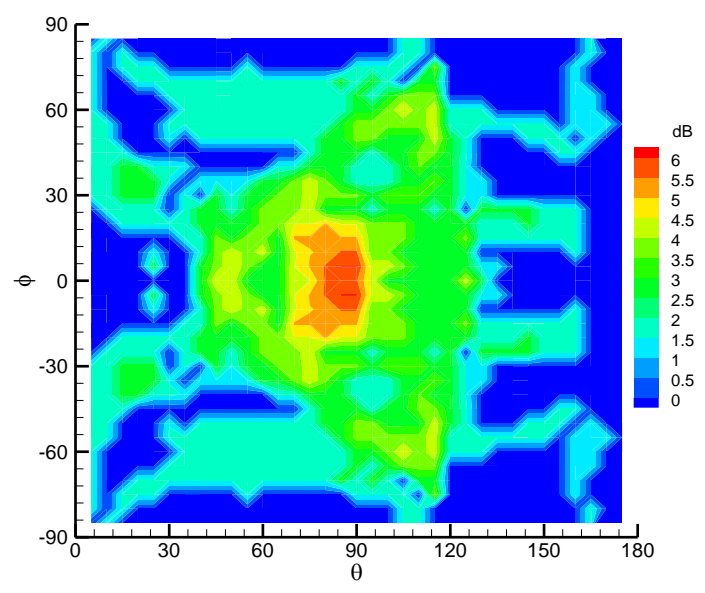

Figure 5. Effects of airframe reflection on main landing gear noise for $T+W$ aircraft.

To compare the reflective properties between HWB and T+W aircraft, the noise increase due to reflection from a HWB aircraft is shown in Figure 6. It is seen that the reflection from the HWB aircraft reaches a larger spatial domain (in both the azimuthal and the polar direction) than for the $\mathrm{T}+\mathrm{W}$ aircraft and that the reflection is relatively uniform and of about $3 \mathrm{~dB}$ for most directions. These differences are explained by the fact that the HWB airframe does not have flaps, and hence, lacks the feature of redirecting sound waves from one direction to another. Instead, the reflection is mostly produced from a large, relatively flat lower surface of the airframe, resulting in the almost uniform noise increase of $3 \mathrm{~dB}$ in most of the directions. It is noted that at the azimuthal directions of about 30 degrees from the flyover plane, there is a higher reflection level of about $4.5 \mathrm{~dB}$ indicated by the light yellow strips. These higher reflection levels are believed to be caused by the position of the landing gears on the airframe. As previously mentioned, the main landing gears are installed on the HWB airframe at the junctions between the center body and the outer wings where the local geometry transitions from the thick center body to the much thinner wings. These local transition surfaces face the sideline direction, and hence, reflect sound away from the flyover plane.

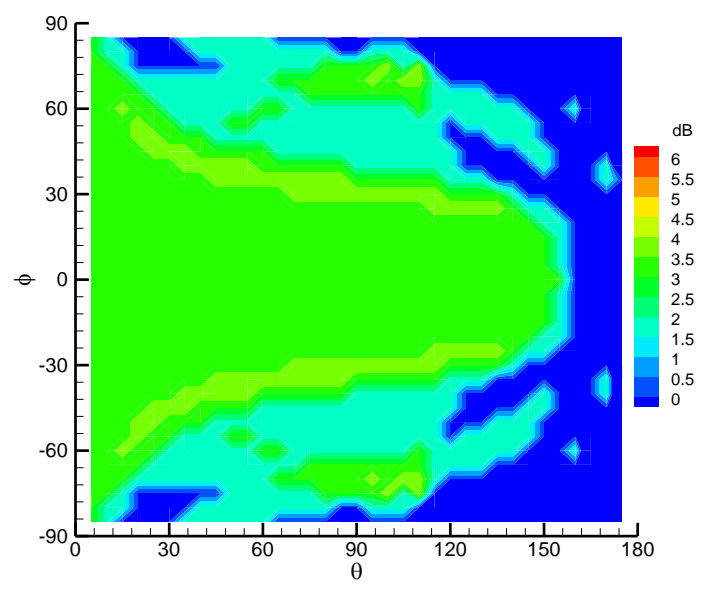

Figure 6. Effects of airframe reflection on main landing gear noise for HWB aircraft. 


\section{Parametric Trends}

There are other improvements in the prediction methodology which are beneficial to both conventional and advanced aircraft configurations. These improvements are due to either better understanding of the modeled features or new data available now. The effects of landing gear truck angle are examples. The prediction models for the gear truck angle effects are plotted in Figure 7 for the three spectral components, respectively, in the low, mid and high frequency domains, with the solid curves for the 6-wheel gears and the dash curves for the 4-wheel gears. The effects are shown as noise increase in decibels, plotted in the figure as a function of the gear truck angle. The noise increase is due to the interactions between the wheels so that the baseline is set at 90 degrees of truck angle when the interactions are minimum. For both types of gears and for all three spectral components, the noise decreases with increasing truck angle. This is intuitive because the maximum interactions between the wheels can be expected when the wheels are aligned with the flow, namely, at zero truck angle, where the aft row of wheels is directly in the wake of the front row. At the other extreme when the wheels are arranged in a line perpendicular to the flow, namely, at 90 degrees truck angle, the wheels have minimum mutual interaction, and hence, minimum interaction noise.

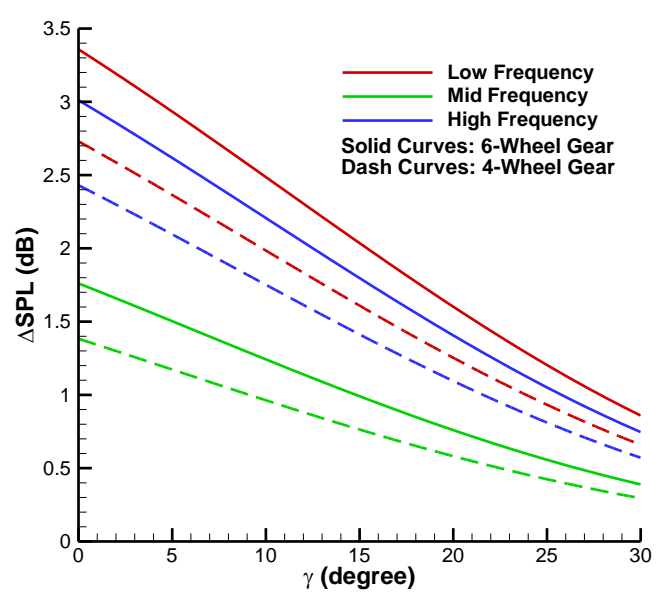

Figure 7 Effects of landing gear truck angle.

The models are developed from the flight test data reported in Refs 11, 14 and 23, known as the Quiet Technology Demonstrator II (QTD2). The test vehicle is a Boeing 777 aircraft that has 6-wheel main landing gears with a truck angle of 13 degrees. The flight tests include configurations where the truck angle is set at either 0 or 13 degrees. These data can be used to identify the effects of gear truck angle variations. An example of the test data is plotted in Figure 8, where the noise spectra at 90 degrees emission angle is shown as a function of frequency, for the truck angles of both zero and 13 degrees. In both flight configurations, the flaps are retracted to minimize other airframe noise components. It is clear from this figure that as the truck angle increases from zero to 13 degrees, there is a noise reduction of about $2 \mathrm{~dB}$ in both the low and the high frequency domains, below about $500 \mathrm{~Hz}$ and above $4000 \mathrm{~Hz}$, respectively, as well as a slight reduction in the mid frequency domain, between 500 and $4000 \mathrm{~Hz}$. These frequency dependent effects are modeled by the three individual spectral components, as shown in Figure 7.

Though the source flow for landing gear noise is very complex, the description of the sources in terms of the acoustic analogy is relatively simple; the unsteady pressure fluctuations on the surfaces of the gear components generate dipole sources whose amplitudes scale with the sixth power of the flow Mach number (Refs 24-26). This Mach number dependence is clearly shown in Figure 9 which plots the normalized Overall Sound Pressure Levels (OASPL) measured (or calculated) at the overhead far field position of 90 degrees (polar emission angle), as a function of flow Mach number. The prediction is given by the solid curve, and the symbols are from various tests which include a small scale model of $6.3 \%$ of the Boeing 777 aircraft main landing gear tested in the NASA Quiet Flow Facility (QFF) [Ref 27], both with and without the gear door, a full scale main gear of the Boeing 737 aircraft tested in the Boeing Low Speed Aeroacoustics Facility (LSAF) [Refs 17 and 18], a full scale main gear of the Airbus 320 aircraft tested in the German-Dutch Wind Tunnel (DNW), in both the 2-wheel and the 4-wheel configurations [Ref 15], a full scale main gear of the Airbus 340 aircraft tested again in DNW [Ref 16], and the QTD2 flight test of the Boeing 777 aircraft. The good agreement between the prediction and measured data is expected because the OASPL is usually predominantly tied to the spectral peak levels, which, for full scale landing gear noise, are in the hundred Hertz range where the acoustic wavelengths are on the order of a few feet, larger than the dimensions of 
most of the gear components. Thus, noise radiations around the spectral peak frequencies are mostly due to compact dipoles, scalable by the six power of the flow Mach number.

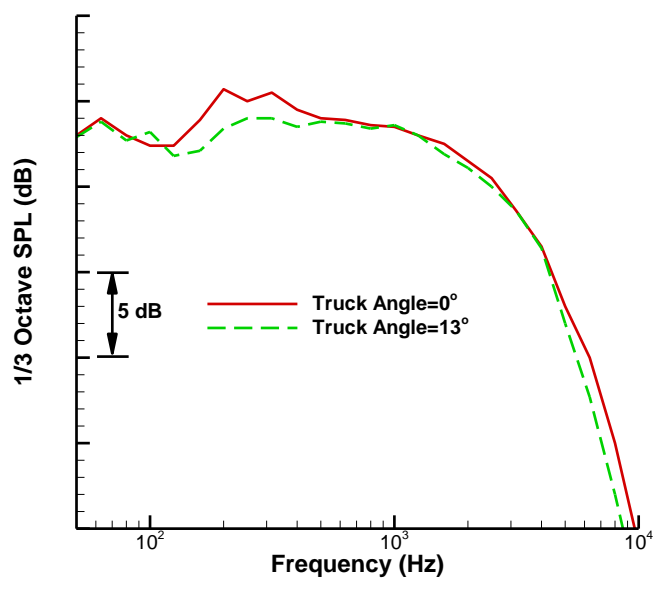

Figure 8 QTD2 test data showing the effects of landing gear truck angle.

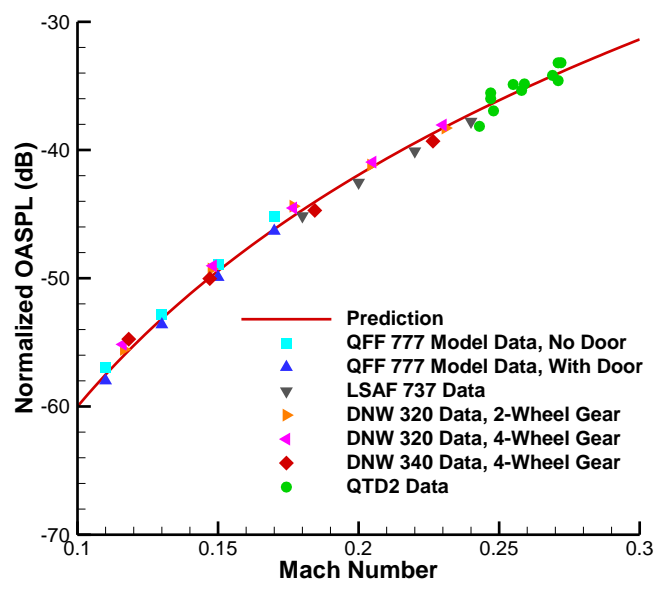

Figure 9 Mach number dependence of landing gear noise.

It is noted that if the Mach number scaling is applied to different frequency domains, other than near the spectral peak frequencies, deviations from the sixth power law can be expected. For example, at high frequencies (a few kilohertz in full scale), for example, the acoustic wavelengths are no longer large in comparison with the landing gear component dimensions. The sources in this case become non-compact, which usually increases the power of the scaling law by one (Refs 25, 26). Indeed, the LSAF test data for the Boeing 737 main gear show a better data scaling at high frequencies with a seventh power (Ref 18).

\section{Validation by Wind Tunnel Tests}

To demonstrate the improved prediction capability, systematic validation cases are presented in this section and the next, using data from various tests. The gear configurations include 2-wheel, 4-wheel and 6-wheel gear designs, essentially all the types used in current commercial transports. The sizes of the gears range from small scale models to full scale gears. While the wind tunnel tests are all for isolated gears, flight tests are included in the validation database, taking into account the full installation effects. The validation cases are summarized in Table 2, where the first six datasets are wind tunnel tests for isolated gears, all of which have been introduced in the previous section, except for the second set from the Railway Technical Research Institute (RTRI) of Japan, which pertained to a 40\% model of a regional jet main gear (as reported in Ref 28). The validations performed with these wind tunnel test data 
are presented in this section. The last four datasets listed in the table are from flight tests, which will be discussed in the following section.

Table 2 Summary of validation datasets

\begin{tabular}{l|ccccc}
\hline \multicolumn{1}{c|}{ Gear Model } & $\begin{array}{c}\text { Number of } \\
\text { Wheels }\end{array}$ & Scale & $\begin{array}{c}\text { Test } \\
\text { Facility }\end{array}$ & Configuration & Reference \\
\hline Boeing 777 & 6 & $6.3 \%$ & QFF & Isolated & 27 \\
Regional Jet & 2 & $40 \%$ & RTRI & Isolated & 28 \\
Airbus 320 & 2 & Full Scale & DNW & Isolated & 15 \\
Airbus 320 & 4 & Full Scale & DNW & Isolated & 15 \\
Boeing 737 & 2 & Full Scale & LSAF & Isolated & 17 \\
Airbus 340 & 4 & Full Scale & DNW & Isolated & 16 \\
Boeing 777 QTD1 & Various & Full Scale & Flight & Installed & 29 \\
Boeing 777 QTD2 & Various & Full Scale & Flight & Installed & 14 \\
Boeing 747 & Various & Full Scale & Flight & Installed & 30 \\
Boeing DC-10 & Various & Full Scale & Flight & Installed & 31 \\
\hline
\end{tabular}

The improvement of the prediction capability includes the extension of prediction to small size landing gears, the lack of which (due to the use of full scale large gear data for some of the empirical modeling used in the original prediction model development) had been identified as a drawback (Ref 6). By applying Strouhal number modeling, this limitation has been removed. A validation case for this new capability is shown in Figure 10, where the predictions and the QFF Boeing 777 small model data are compared. Noise spectra are shown as a function of frequency for various flow Mach numbers. The predictions are obtained for the precise wind tunnel test configuration, i.e., for a $6.3 \%$ model and a microphone positioned at a 90 degree polar emission angle, 5 feet away from the model. The agreement between the predictions and measured data is good, both in the spectral shapes and in the absolute amplitudes. The increase of noise levels with flow Mach number is correctly predicted as well.

To illustrate the prediction of directivity patterns, the OASPL from both the predictions and the QFF data are compared in Figure 11. OASPL from the QFF data are shown with red square symbols for the azimuthal angles and with blue diamond symbols for the polar angles, while the predicted data are shown with correspondingly colored curves. The coordinates are defined in the same way as that in Figure 5 and Figure 6 . It is seen in Figure 11 that the azimuthal directivity of the gear noise is almost flat, with a slight increasing trend with the azimuthal angle due to the asymmetry of the gear design; the quadrant with slightly higher noise corresponds to the side of the gear where the side bars or braces are located. There is a more noticeable change in noise levels in the polar directivity, with higher noise seen in the forward quadrant, a result of convective amplification, which is a common feature in the flyover plane, as will be shown for other test cases.

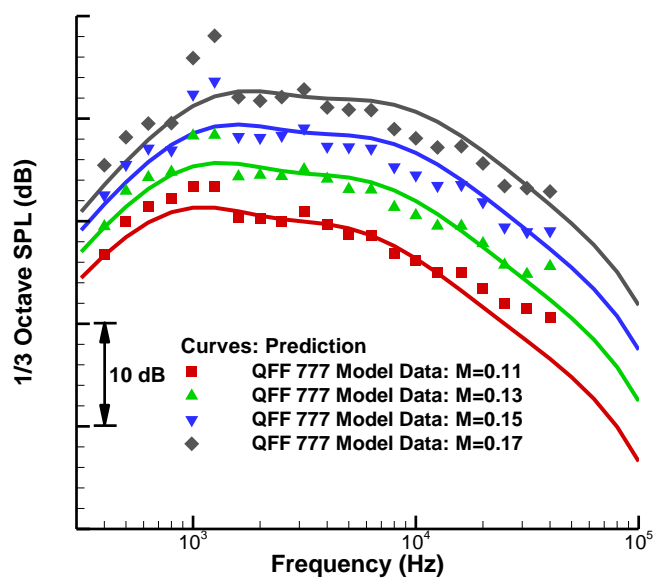

Figure 10. Validation by QFF 6.3\% Boeing 777 model data. 


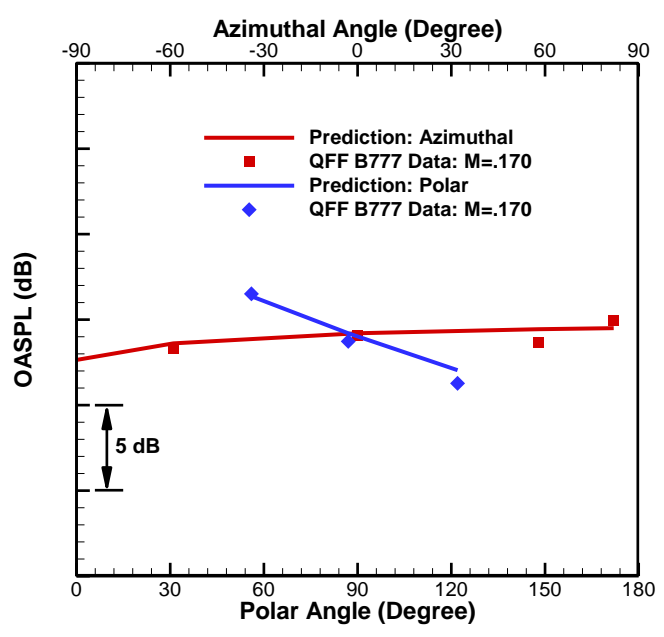

Figure 11. Directivity patterns of QFF 6.3\% Boeing 777 model data.

The capability to predict noise for small landing gears is not only for the use of wind tunnel test configurations. More importantly, it is a capability that will be used for the prediction of landing gear noise from small aircraft such as regional jets and general aviation aircraft, which represent an important segment of aviation. It is further noted that small aircraft landing gears are not simple scaled-down versions of larger aircraft gears. In general, small aircraft landing gears are less complex in structural design than for large aircraft, because of lighter aircraft weight and slower speed. To demonstrate this application, Figure 12 shows comparisons between predicted and test data for a $40 \%$ main gear of a regional jet aircraft, at a 90 degree emission angle (Ref 28). The test data include both free field microphone measurements and phased microphone array measurements, both showing good agreement with the prediction.

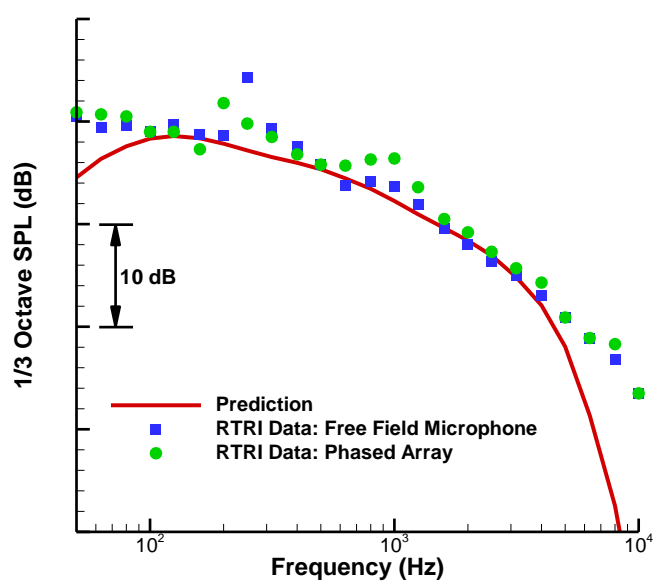

Figure 12. Validation by RTRI $40 \%$ regional jet gear model data.

There have been a few wind tunnel tests performed with full configuration landing gears that have provided good data for the understanding of landing gear noise and for the development of prediction tools. Figure 13 shows an example of validation of the present model against the data from DNW, based on a full scale 2-wheel main gear of the Airbus 320 aircraft (Ref 15). The figure shows the comparisons of noise spectra between predictions and data for various flow Mach numbers at the overhead location of 90 degrees emission angle. Similar comparisons are shown for the Airbus 320 main gear with four wheels in Figure 14. In both cases, good agreements are clearly seen, in the spectral shapes, the noise levels, and the Mach number dependences.

In the DNW tests with the Airbus 320 landing gears, measurements are also available at the emission angle of 66 and 133 degrees in the flyover plane, and the good agreements shown in Figure 13 and Figure 14 for the 90 degree emission angle are representative of that achieved at the other angles. The correct modeling of the angular variations 
of the landing gear noise is illustrated in Figure 15 in terms of OASPL as a function of the polar angle at various flow Mach numbers, where the curves are the predictions and the symbols are the test data, with the solid curves and closed symbols for the 2-wheel gear and the dash curves and open symbols for the 4-wheel gear.

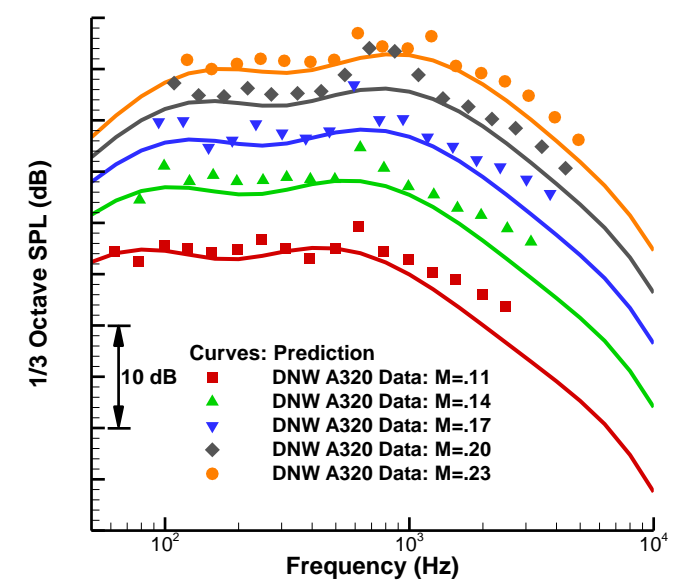

Figure 13. Validation by DNW Airbus 320 2-wheel full scale gear data.

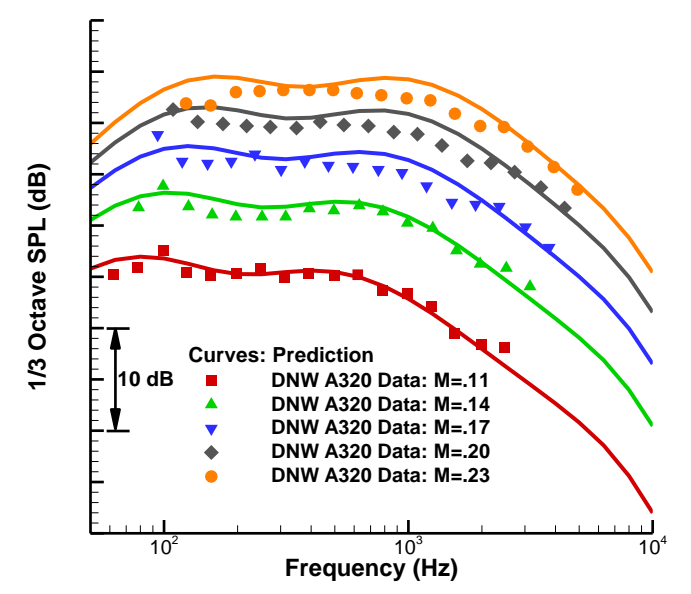

Figure 14. Validation by DNW Airbus 320 4-wheel full scale gear data.

Similarly, predictions are also validated by the LSAF Boeing 737 full scale main landing gear data, which is demonstrated in Figure 16 and Figure 17, the former being the noise spectra at the overhead location of 90 degrees emission angle as a function of frequency and the latter the OASPL as a function of the polar angle in the flyover plane, both for four different flow Mach numbers. This is the database used in the original development of the prediction methodology reported in Refs 3 and 4. It contains a large number of variations in gear configurations, test conditions, and measurement locations, with details given in Refs 17 and 18. Validations have also been done with these variations, and the comparisons shown in Figure 16 and Figure 17 are very representative of other cases.

It can be noted that the directivity in Figure 17 shows an almost straight line decrease in noise levels in most of the polar angle domain, which differs from what is usually plotted with a peak angle and gradual falloff on both sides of the peak. This is due to the fact that the predictions and comparisons in this figure are for the wind tunnel configuration where the microphones are located on a line near the landing gear, the closest microphone being 9.7 feet from the gear center. Thus, the microphones are not in the true far field of the gear so that the effects of spherical spreading and atmospheric absorption are not fully reflected in the data; if the data are extrapolated to the far field, the noise levels away from the 90 degree direction would decrease more, leading to the usual directivity pattern. It should also be noted that the test facility of LSAF has a low frequency cutoff of about $200 \mathrm{~Hz}$, which is about the peak frequency for full scale landing gears. Thus, the levels of OASPL shown in Figure 17 may have 
missed parts of the spectral peak. Furthermore, the test data contain tones from some gear components that are usually not seen for installed gears. Both of these have been discussed in detail in Refs 17 and 18, and may be the reason for the relatively large discrepancies between predictions and data shown in Figure 17 for the OAPSL levels.

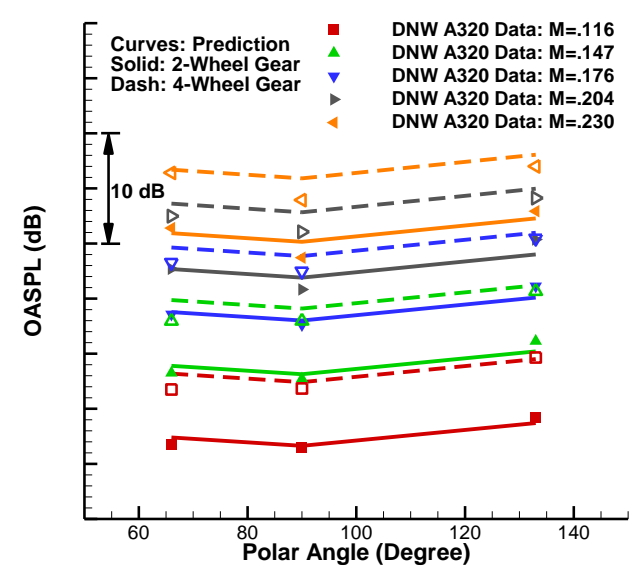

Figure 15. Directivity of DNW Airbus 320 2-wheel and 4-wheel gear.

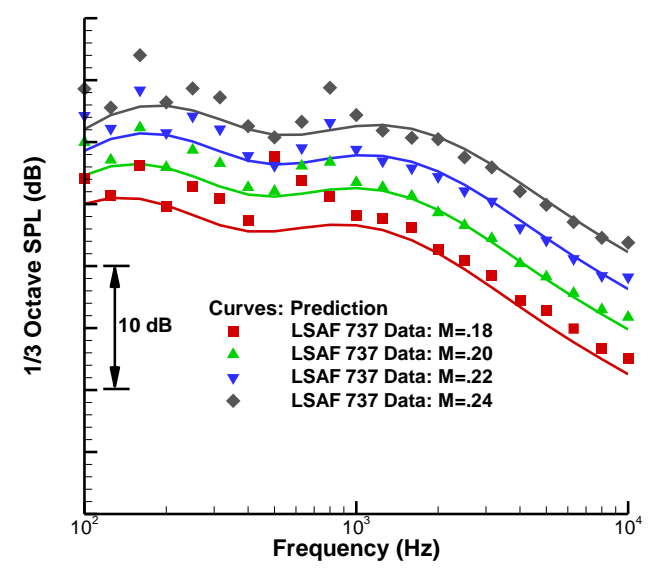

Figure 16. Validation by LSAF Boeing 737 main gear data.

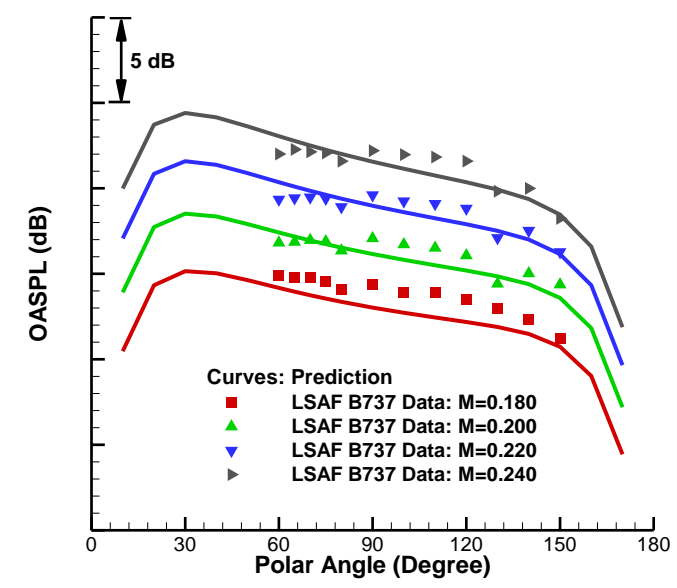

Figure 17. Directivity patterns of landing gear noise for the Boeing 737 main gear.

American Institute of Aeronautics and Astronautics 
For a gear of larger size than the Airbus 320 and Boeing 737 gears, the model validation is shown in Figure 18 for the Airbus 340 main gear with 4 wheels, tested in DNW (Ref 16). Similar to previous comparisons for other gears, the figure plots the noise spectra as a function of frequency for four different flow Mach numbers. The measurement location is the overhead position at 90 degrees emission angle in the flyover plane. The agreements between the predictions and data are also consistent with other comparisons, in the spectral shape, the Mach number dependence and the absolute amplitude.

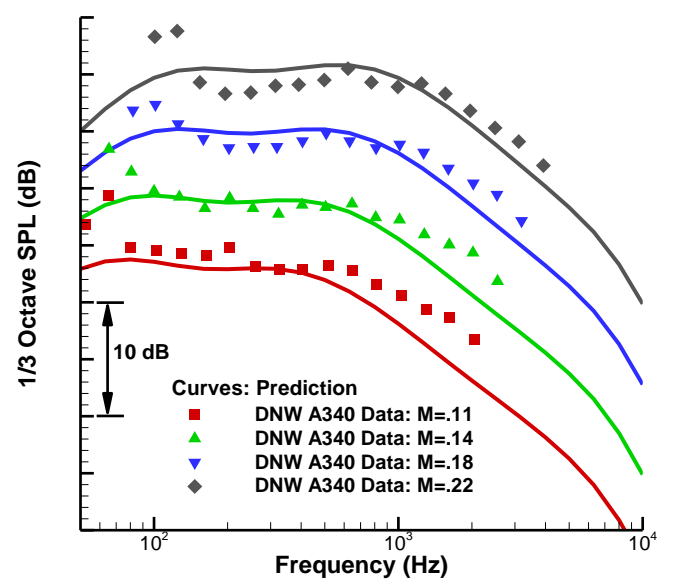

Figure 18. Validation by DNW Airbus 340 4-wheel gear data.

\section{Validation by Flight Tests}

The validation cases presented in the previous section were all for wind tunnel tests with isolated landing gears, which have the advantage of explicitly bringing out the noise source mechanisms and noise characteristics of the tested models without the complexity of multiple sources. The drawback of the wind tunnel test data is the lack of installation effects, which are an important part of total landing gear noise. Installation effects manifest themselves in various aspects, one being the local flow effect and the other the reflection of noise from the aircraft. These two effects have been discussed individually in previous sections. In this section, validations are shown with aircraft flight test data that account for the collective installation effects.

The flight test data used for validation are listed in Table 2 as the last four datasets. The first two are known as the Quiet Technology Demonstrator 1 and 2 (QTD1 and QTD2), which respectively used the Boeing 777-200 and 777-300 aircraft (Refs 11, 14, 29). The third dataset is from a flight test of the Boeing 747-400 aircraft (Ref 30), and the last involves the Boeing DC-10-10 aircraft (Ref 31). The flight test data contain contributions from both the nose and the main gears, as well as all the installation effects. Full configuration flight tests also inevitably include other noise sources. Thus, landing gear noise data from flight tests are usually derived from the differences of gear-down and gear-up flight configurations. Because landing gear noise is incoherent with other noise components, this subtraction of the acoustic pressure fields measured from the two configurations is acceptable as long as landing gear noise is a dominant noise component.

The comparisons between predictions and the QTD1 flight test data are illustrated in Figure 19 and Figure 20. The former shows noise spectra as a function of frequency at three emission angles in the flyover plane, 60 degrees in the forward quadrant, 90 degrees for the overhead position and 120 degrees in the aft quadrant, while the latter plots the directivity patterns of the data as a function of the polar angle, together with the predicted directivity. Two sets of data are shown in Figure 20, corresponding to the landing gear noise with the flap settings respectively at 30 and 25. There are only slight differences between the two. This is expected because the noise sources due to the landing gears are independent of the flap settings, which can affect the radiated gear noise only through the installation effects. In the cases shown in Figure 20, however, the differences in the installation effects are small due to the small variations between flap 25 and flap 30, leading to small differences in the noise levels. The comparisons in both these figures clearly show that the spectral shapes, the amplitudes and the directivities of the Boeing 777-200 landing gear noise are well predicted by the models. 


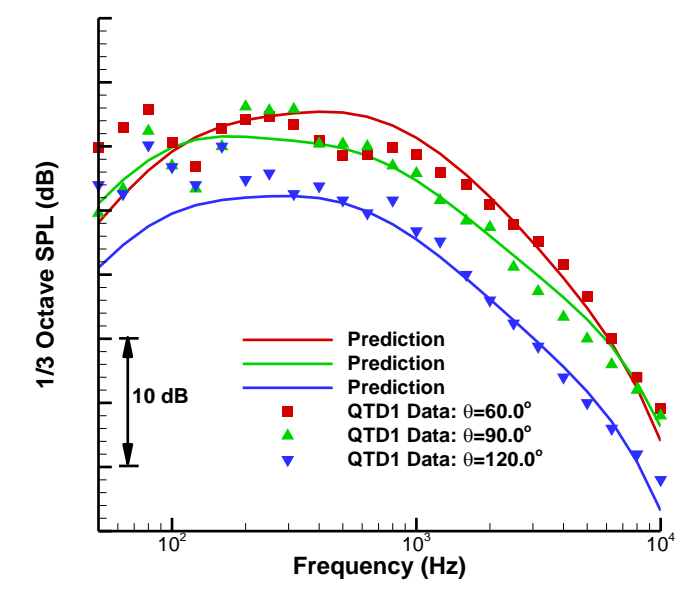

Figure 19. Validation by QTD1 Boeing 777-200 flight test data.

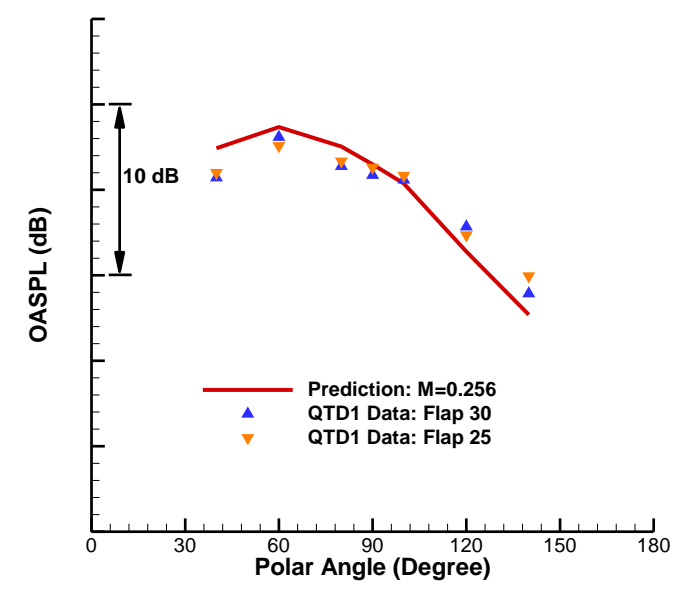

Figure 20. Directivity variation of QTD1 Boeing 777-200 flight test data.

Similar comparisons with the QTD2 flight test data for the Boeing 777-300 aircraft are shown in Figure 21 and Figure 22, with similarly good agreements between predictions and data. It can be noted that the flight test data, for both QTD1 and QTD2 tests, have more scatter in comparison with wind tunnel data for isolated gear discussed in the previous section. This is mostly due to the fact that the landing gear noise data for flight tests are not direct measurements; instead, they are derived by the differences of the measurements for the gear-down and the gear-up flight configurations, while the wind tunnel tests directly measure the gear noise. The subtraction between two configurations is sensitive to the presence of other noise components, as well as variations in flight test conditions, such as flight speed, altitude and weather. The latter is usually normalized to a standard set of conditions, but the normalization itself is based on approximations of the parametric trends, which inevitably induces variations in the data. These variations are usually small enough to be negligible for practical purposes. This is also clearly shown by the spectral data in Figure 19 and Figure 21; the data scatter is more noticeable at the position of 120 degrees emission angle where the landing gear noise levels are relatively low and the total aircraft noise is probably influenced by other components.

The Boeing 747 aircraft has some unique features in terms of landing gear noise; it has a pair of body gears installed under the fuselage. Though the structural design of the body gears can be considered similar to the main gears that are installed under the wings, their heights are smaller, due to the shorter distance between the fuselage and the ground than the distance between the wing and the ground. This reduces the gear noise. On the other hand, the fuselage is not a lifting element so that the flow under the fuselage is not affected by the circulation around the wings, and hence, its velocity is not reduced, as is the case for the main gears. This increases the gear noise. Another 
unique feature for the Boeing 747 landing gear noise is the reflection of the body gear noise by the fuselage, which is locally almost flat and produces a strong reflection in the flyover plane. These features lead to the dominance of the body gears in the total 747 gear noise. Some comparisons between the test data (Ref 30) and the predictions that include all these features are shown in Figure 23 for the noise spectra at three emission angles in the flyover plane. The flight Mach number in this case is 0.3 and the gear noise includes contributions from all five gears, which are one nose gear, two main gears and two body gears.

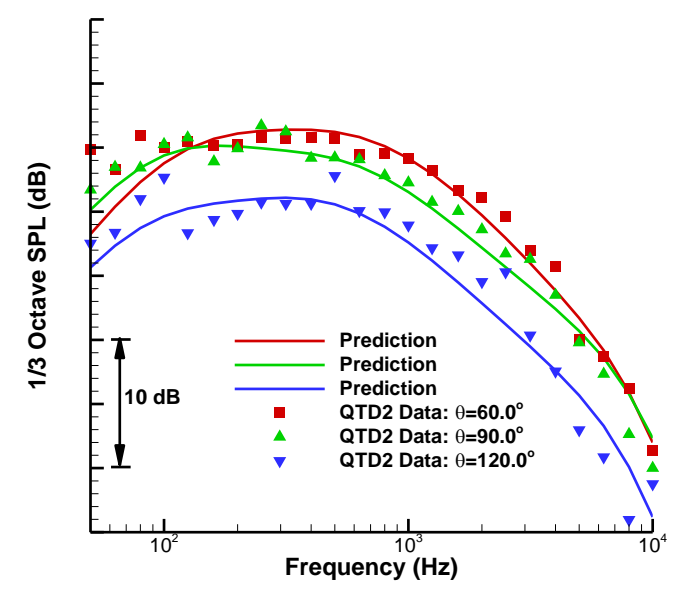

Figure 21. Validation by QTD2 Boeing 777-300 flight test data.

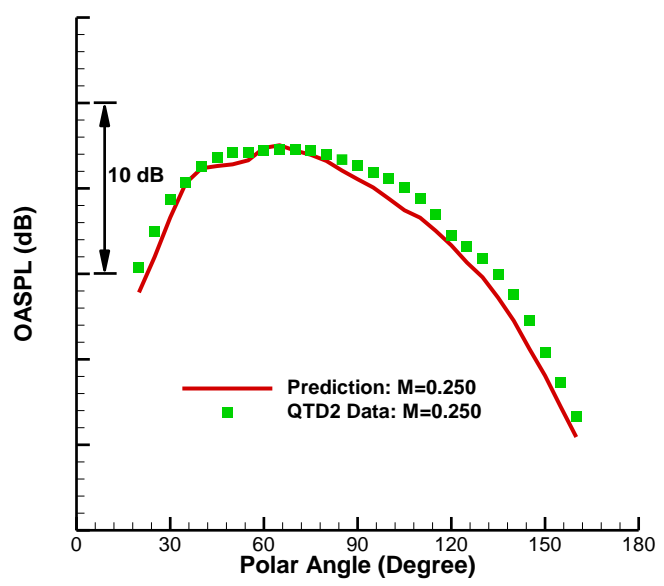

Figure 22. Directivity variation of QTD2 Boeing 777-300 flight test data.

Similar to Figure 23, some comparisons between the test data of Ref 31, for the DC-10-10 aircraft, and the predictions are shown in Figure 24, for the noise spectra of three emission angles in the flyover plane, with a flight Mach number of 0.27. Though data scatter is noticeable at various frequencies, as is also the case for other flight test data, the overall agreements between the predictions and data are satisfactory. It is noted that in all the validation cases presented in the present and previous sections, no amplitude adjustments were made; the predictions are quantitative for the absolute levels, even though the axes are not labeled with absolute values. 


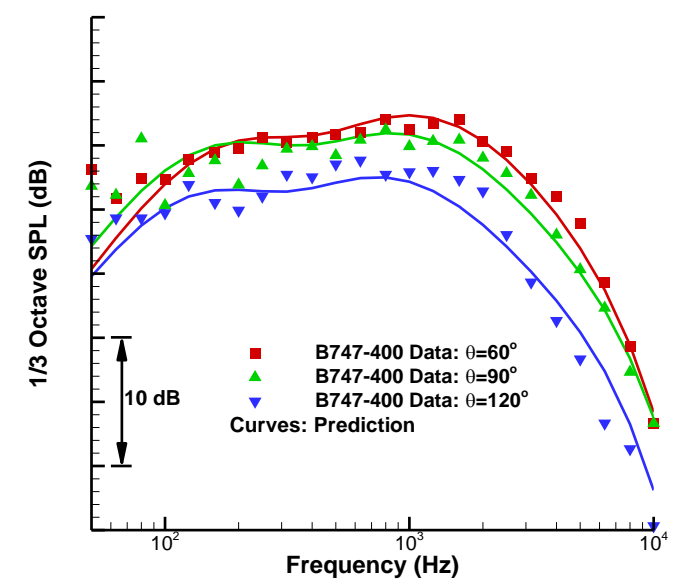

Figure 23. Validation by Boeing 747-400 flight test data.

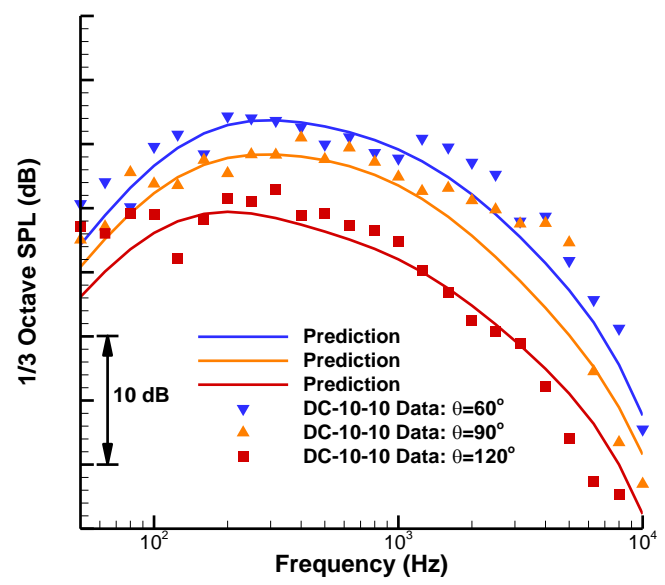

Figure 24. Validation by Boeing DC-10-10 flight test data.

\section{Landing Gear Noise of ERA Aircraft}

Having validated the prediction capability with a large number of test datasets, this section will discuss the application of the landing gear prediction capability (herein referred to as the Guo-LG method) to the large twin aisle (LTA) class of $2025 \mathrm{~N}+2$ aircraft concepts studied in the NASA ERA Project (Ref 32). The improved prediction capability has been integrated within NASA's Aircraft NOise Prediction Program (ANOPP), which remains as part of the new ANOPP2 - a multi-fidelity aeroacoustics prediction framework. For the large twin aisle (LTA) aircraft class, the designs include 3 configurations:

1. conventional $\mathrm{T}+\mathrm{W}$ with engines mounted under the wings ( $\mathrm{T}+\mathrm{W} 301-\mathrm{GTF})$,

2. $\mathrm{T}+\mathrm{W}$ with engine mounted at mid-fuselage (MFN301-GTF), and

3. hybrid wing body with the engines on the upper surface of the body (HWB301-GTF).

These are all shown in Figure 25. These concept vehicles are designed with the same constraints and mission requirements as an optimized reference aircraft, which for the LTA class is the NASA reference 777-200LR-like vehicle as defined in Ref 33. The landing gear design for each of these aircraft is based on the geometry similar to that of the Boeing 777 aircraft, which has two 6-wheel main landing gear assemblies and one 2-wheel nose gear assembly (Ref 32). The integration of the landing gear assemblies with the airframe requires constraints for accommodating nose gear collapse and to avoid aircraft tail scrape. The main struts of both the nose and main landing gear depend on the aircraft configuration and are given Table 3 for each aircraft, along with the specific gear assembly $\mathrm{x}_{\text {gear }}$ relative to the nose of the aircraft normalized by the respective fuselage length $\left(\mathrm{L}_{\text {fuselage }}\right)$. The takeoff gross weight (TOGW) and the aircraft angle of attack, $\alpha$, and speed are also provided for comparison. The main gear 
strut on the T+W301-GTF and the Reference (777-200LR-like) are sized to accommodate the large diameters of the engines for those aircraft. They are also about twice as long as the strut length of the aircraft MFN301 and HWB301, for which the engines are mounted over the wing or fuselage.

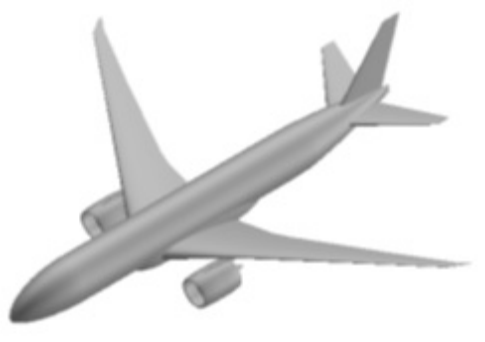

$\mathrm{T}+\mathrm{W} 301-\mathrm{GTF}$

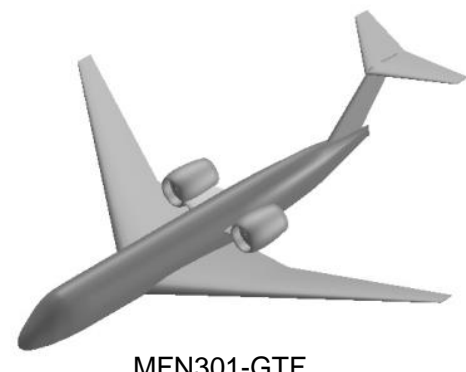

MFN301-GTF

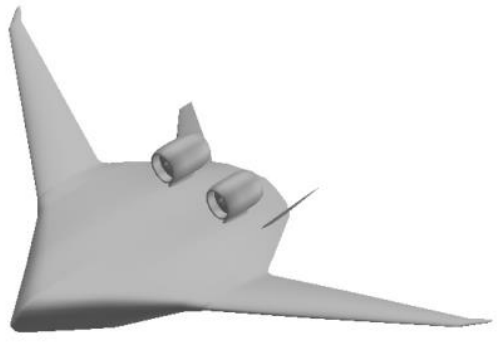

HWB301-GTF

Figure 25. ERA large twin aisle aircraft configurations.

Due to the aero performance characteristics of each aircraft, its approach speed and aircraft angle of attack vary. The T+W aircraft have similar values for both the speed and $\alpha$. However, the HWB301 is about 7\% slower than the T+W301 and MFN301 and with $\alpha$ about 10 degrees higher. As shown earlier in the paper these are all key parameters affecting the gear noise amplitude and its directivity.

Table 3. ERA vehicles and their flight conditions

\begin{tabular}{c|ccccccc}
\hline \multicolumn{1}{c|}{ Aircraft } & $\begin{array}{c}\text { TOGW } \\
(\text { Klbs })\end{array}$ & $\begin{array}{c}\text { Wing Span, } \\
(f t)\end{array}$ & $\begin{array}{c}x_{\text {gear }} / \text { Lfuselage } \\
(N G, M G)\end{array}$ & $\begin{array}{c}\text { MG Strut } \\
\text { Length }(f t)\end{array}$ & $\begin{array}{c}\text { NG Strut } \\
\text { Length }(f t)\end{array}$ & $M$ & $\begin{array}{c}\alpha \\
(\text { deg })\end{array}$ \\
\hline Ref: 777-like & 766 & 213 & $0.07,0.41$ & 17.5 & 12.2 & 0.197 & 10.1 \\
T+W301-GTF & 571 & 223 & $0.08,0.51$ & 19.2 & 13.4 & 0.206 & 3.3 \\
HWB301-GTF & 535 & 250 & $0.28,0.57$ & 7.4 & 5.2 & 0.191 & 14.7 \\
MFN301-GTF & 541 & 175 & $0.08,0.51$ & 9.6 & 6.7 & 0.206 & 3.8 \\
\hline
\end{tabular}

Prior to the availability of the Guo-LG method, the landing gear noise prediction contained in the Boeing Airframe Module (BAF) in ANOPP was used almost exclusively for predicting the airframe noise for aircraft system noise studies at NASA. The ANOPP-BAF (Ref 6) module was developed and implemented in ANOPP in 2006 and includes capabilities to compute not only landing gear noise, but also options for slat and flap side-edge noise prediction (Ref 34). The ANOPP-BAF gear method was formulated by Guo (Refs 3, 4, 34) and is similar in approach to the new Guo-LG method in that the gear noise directivities are defined based on the size of the gear elements. This was for limited gear designs, and the installation effects of local velocity for HWB aircraft were not available. In addition, an empirical model to account for fuselage/wing reflection and diffraction was largely developed from physical reasoning and calibrated with limited data. The maximum increase in far-field noise due to the installation effects was restricted to less than $3 \mathrm{~dB}$, which would represent reflection from an infinite plate. With the availability of the Guo-LG method, which is based on and validated with a much larger set of computational and experimental (wind tunnel and flight) data for a larger range of gear designs, it is expected that the noise predictions for isolated and installed gear will be more accurate.

The difference in Effective Perceived Noise Level (EPNL) between Guo-LG and ANOPP-BAF ( $\triangle \mathrm{EPNL}$ ) is used to compare the two methods. The noise is computed for the nose, main and total gear (main + nose) of each aircraft listed in Table 3. For the Guo-LG method, predictions are made without and with the effect of reflections from the airframe, respectively shown in Figure 26 and Figure 27. The nose gear EPNL for each aircraft is on the order of at least 15 EPNL dB less than the main gear but is shown to indicate the difference between ANOPP-BAF and GuoLG prediction levels. Without including the effect of reflections, the Guo-LG EPNL levels are on the order of 1 to 1.5 EPNL dB less that that obtained from ANOPP-BAF. However, when accounting for the effect of reflections from the fuselage, wing and high-lift systems $(\mathrm{T}+\mathrm{W}$ aircraft include both flaps and leading-edge Krueger flaps, HWB301 has leading-edge Krueger flaps but no flaps) the Guo-LG predictions are higher than that predicted by ANOPP-BAF, as shown in Figure 27. The Reference 777-like aircraft Guo-LG predictions are nearly the same as ANOPP-BAF. However, for the T+W and MFN301, the Guo-LG method predicts on the order of $2 \mathrm{~dB}$ higher for the T+W301-GTF to nearly $4 \mathrm{~dB}$ higher in level for the MFN301-GTF. The T+W301-GTF is similar in design to the 777-200LR-like vehicle, but the main strut length is longer, and this locates the main truck assembly in a higher 
local flow velocity. The increased levels for the MFN301-GTF are mainly due to the increased surfaces of the inboard wing and flap area, producing increased reflection levels. As mentioned in section III, the reflections from the HWB airframe are mostly from the large flat undersurface of the airframe, resulting in roughly $3 \mathrm{~dB}$ increase at most angles. For the HWB301-GTF the difference is slightly more than $3 \mathrm{~dB}$ at about $3.5 \mathrm{EPNL} \mathrm{dB}$ (difference between result shown in Figure 26 and Figure 27), due to the airframe reflection.

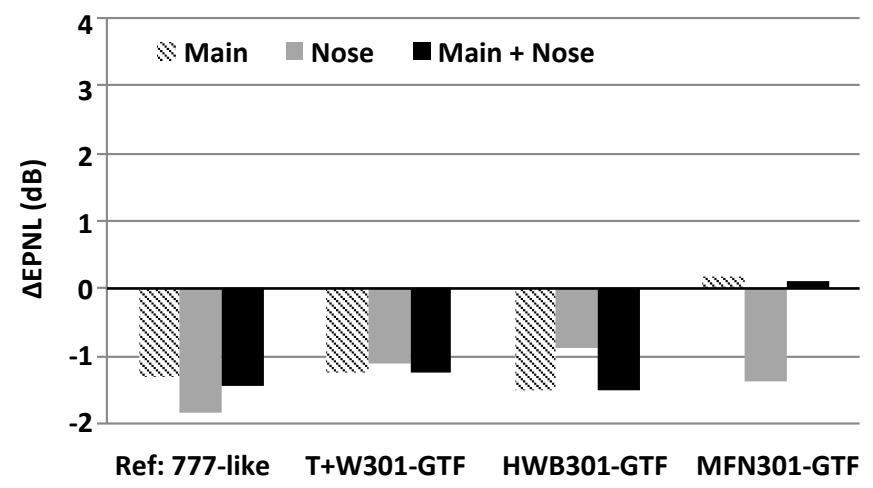

Figure 26. The difference in predicted landing gear noise, $\triangle E P N L=($ Guo-LG $)-($ ANOPP-BAF $)$, where GuoLG does not include effect of airframe reflections.

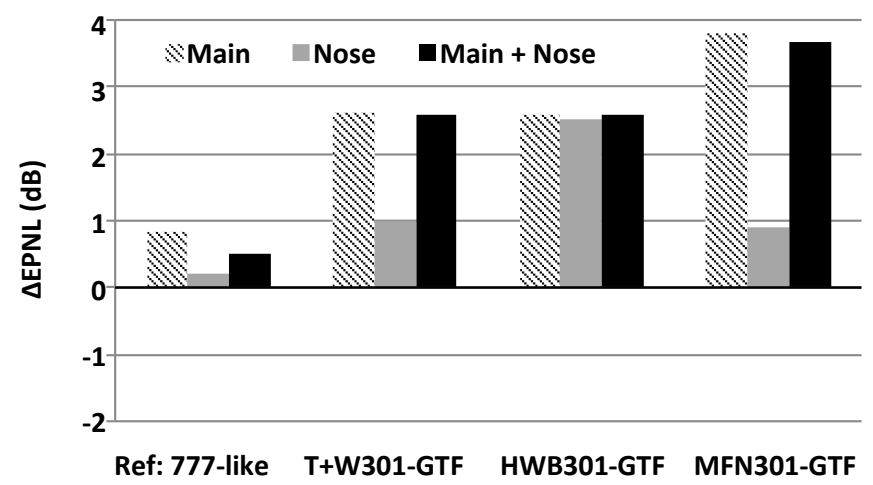

Figure 27. The difference in predicted landing gear noise, $\triangle \mathrm{EPNL}=($ Guo-LG $)-($ ANOPP-BAF $)$, where GuoLG includes effect of airframe reflections.

\section{Uncertainty Analysis}

Obviously, predictions always involve uncertainties, especially predictions for future aircraft. The uncertainties can result from various factors such as design deviations, operations condition variations, imprecise modeling parameters, etc. In this section, the effects of imprecise modeling parameters will be discussed to reveal their impact on the predicted noise. This is done by the method of Monte Carlo simulation. The process involves first the selection and definition of the uncertainty factors in the prediction models, which, for the study reported in this section, are all assumed to have random variations with normal distributions. The second step is then to run the prediction models with the random variations in the modeling parameter, leading to predictions that also have random variations. The results are then used to compute the statistic measures of the predicted noise. The most commonly used statistic is the standard deviation, though other metrics are also computed and discussed below.

In the previous sections, the prediction models are used to calculate the noise spectrum, as a function of the far field frequency and directivity angle. If the impacts of modeling uncertainties are assessed on these calculations, the results will be a large set of data, especially if the number of uncertainty factors is large. To simplify the discussions, the results for the noise spectra are used further to calculate EPNL. The noise metric then becomes a single parameter. To further facilitate the discussions, the uncertainty analysis will be focused on an HWB configuration that is of size and functionality similar to the Boeing 777 aircraft. The EPNL will be calculated for the approach condition for aircraft certification. Thus, the relevant parameters for landing gear noise prediction are the flight Mach number of 0.2 , aircraft angle of attack of 12 degrees, and a flight path of 3 degrees. 
The landing gear noise prediction models involve various parameters, as detailed in Refs 3 and 4, of which, eight have been identified to have uncertainty variations. Since these parameters model various aspects of the landing gear noise generation, the impacts of the variations in these parameters manifest themselves in various parts of the prediction. Table 4 lists the parameters, together with their respective impact on different aspects of the noise prediction and their respective uncertainty model. The first column lists the eight modeling parameters, followed by the next three columns representing their respective impact on the noise levels, the spectra and the noise directivity. The last two columns show the random variation models used in the analysis; all the parameters are modeled as having a random normal distribution whose standard deviation is given in the last column.

Table 4. Uncertainty modeling parameters and their impact on noise prediction.

\begin{tabular}{|c|c|c|c|c|c|}
\hline & \multicolumn{3}{|c|}{ Impact on Noise } & \multicolumn{2}{|c|}{ Uncertainty Model } \\
\hline & Level & Spectrum & Directivity & $\begin{array}{c}\text { Random } \\
\text { Distribution }\end{array}$ & $\begin{array}{l}\text { Standard } \\
\text { Deviation }\end{array}$ \\
\hline Local Mach Number & $\sqrt{ }$ & $\sqrt{ }$ & - & Normal & $1 \%$ \\
\hline Peak Amplitude & $\sqrt{ }$ & - & - & Normal & $20 \%$ \\
\hline Spectral Shape & - & $\sqrt{ }$ & - & Normal & $15 \%$ \\
\hline Directivity & - & - & $\sqrt{ }$ & Normal & $10^{\circ}$ \\
\hline Complexity Factor & $\sqrt{ }$ & - & - & Normal & $20 \%$ \\
\hline Length Scale & $\sqrt{ }$ & $\sqrt{ }$ & - & Normal & $10 \%$ \\
\hline Source Size & $\sqrt{ }$ & - & $\sqrt{ }$ & Normal & $10 \%$ \\
\hline Truck Angle Factor & $\sqrt{ }$ & - & - & Normal & $10 \%$ \\
\hline
\end{tabular}

It is pointed out that the impact of a parameter on noise as listed in this table is only in the sense that the parameter directly affects the modeling of the listed noise features; of course, their impacts will propagate all the way to the final results. It is also noted that the landing gear noise predictions include three spectral components and include both the main and the nose gear, yielding six noise components. The combination of the six noise components and the eight modeling parameters listed in Table 4 gives a total of 45 uncertainty factors (the gear truck angle does not apply to the nose gear). All these uncertainty factors are modeled independently. Needless to say, there are no well-defined rules for the selection and definition of the random variation models in uncertainty analysis. It largely relies on engineering experience, namely, the experience on how the parameters affect the noise modeling and prediction. In most cases, the approach of trial-and-error is inevitable, and the reasonableness of a model very much depends on physics-based reasoning.

The local flow Mach number can serve as a good example to illustrate this. The need for selecting this parameter is clear; it is one of the dominant parameters controlling the noise prediction because of the sixth power law dependence. From Section II, it is seen that the local flow Mach number is modeled by using CFD data for some defined HWB configurations. The HWB designs can be regarded as being representative of future HWB aircraft, but are by no means final and definitive. Because of this, the local flow Mach number model inevitably involves uncertain variations. These variations are modeled here as a random normal distribution with a standard deviation of $1 \%$, as summarized in Table 4 . To justify the choice of the $1 \%$ standard deviation, the local flow Mach number models shown in Figure 3 are replotted here as Figure 28 with the choice of $1 \%$ standard deviation indicated in the figure. By definition, the $1 \%$ standard deviation in the normal distribution corresponds to significant variations of the Mach number within a range of $\pm 2 \%$ on both sides of the mean value. In the figure, the mean value of the Mach number for the case of 12 degrees angle of attack is shown by the dash line and the range of $\pm 2 \%$ from this mean value is indicated by the two solid lines. The physical meaning of this variation range now becomes clear. In terms of the physical distance from the aircraft, represented by the horizontal axis in the figure, the region between the two solid lines covers the entire curve marked by the left pointing triangles for the case of 12 degrees angle of attack, meaning that the entire range of the physical distance for landing gear source locations is covered by the variation range defined by the chosen $1 \%$ standard deviation for the random uncertainty model. It can also be seen that the two solid lines in the figure bracket the range of angles of attack from below 10 to above 14 degrees for the source locations between about 65 and 200 inches, which is sufficient to cover the uncertain variations due to the angle of attack.

Another example to illustrate the uncertainty parameter model is the spectral shape, which is modeled as a random normal distribution with a $15 \%$ standard deviation. This parameter models the spectral shapes of the three noise components, namely, the low, the mid and the high frequency noise components. Of course, the noise spectra are also determined by the peak amplitudes and the peak frequency, both being accounted for by other parameters in 
the prediction models. For the spectral shapes, the uncertain variations affect the falloff of the shapes on both sides of the peak frequency. This is illustrated in Figure 29, which plots the spectral shape variations for the low frequency component, shown as normalized spectral shapes as a function of the Strouhal number. The solid curve is the baseline case corresponding to the mean value of the random variations, while the two other curves are respectively the lower and the upper bound of the spectral shape given by the variations defined by the $15 \%$ standard deviation in the random distribution of the spectral modeling parameter. Quantitatively, the variations correspond to a $6 \mathrm{~dB}$ range at the $10 \mathrm{~dB}$ down point of the spectral shape, as indicated by the two solid horizontal lines in the figure.

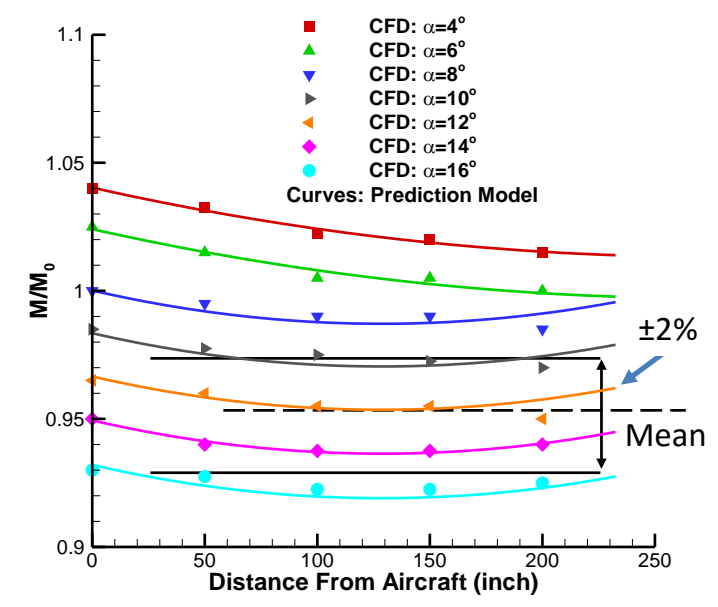

Figure 28. HWB main gear local flow Mach number with variation range.

The complexity factor is also an interesting parameter which is defined to have a large standard deviation of $20 \%$, as can be seen from Table 4 . This is a parameter used to model the effects of small irregular details in the landing gear assembly, which are too difficult for deterministic modeling and yet too important for the high frequency noise to be neglected. The model itself is statistical and is developed based on the current generation of landing gears. In recognizing the significant contributions of the small structural details to the total landing gear noise, it can be expected that future gear designs will be in the direction of reducing the number of small features in the gear assembly, such as holes, cutouts, steps, wires, braces, etc. Thus, the complexity factor model will be subject to modifications and improvements in the future, which for now can be considered as an uncertainty factor. To explain the uncertainty model used here, it can be pointed out that the $20 \%$ standard deviation corresponds to $\pm 40 \%$ of the number of small features in the gear assembly, which is probably sufficient to cover the design trends in the next decade or so in the time frame of the NASA ERA N+2 aircraft. The variations in the number of small structural features can be directly translated to noise level variations, between -2.2 and $+1.5 \mathrm{~dB}$ for the high frequency component, on the spectral level.

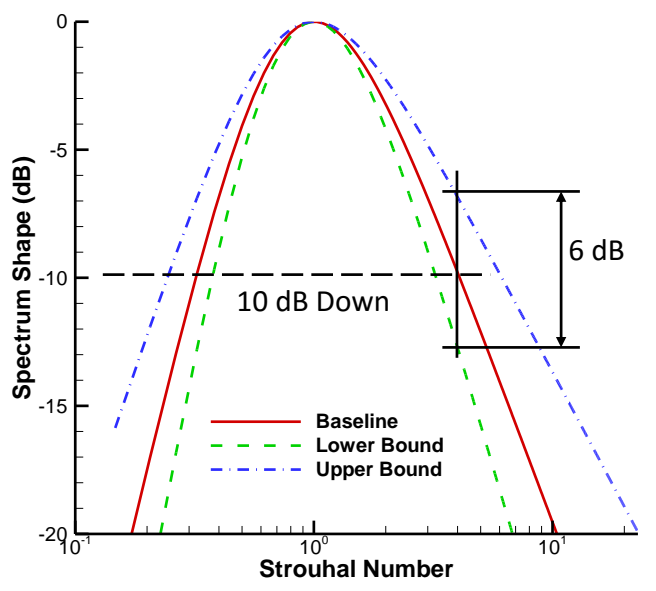




\section{Figure 29. Spectral shape variations for the low frequency component.}

With the uncertainty models defined, the Monte Carlo simulations use random samples from the 45 statistically independent uncertainty factors in the prediction. The results are shown in Figure 30 where the EPNL of the total landing gear noise is plotted as a function of the sampling number in the Monte Carlo simulation. The simulation consists of 20000 samples and the mean value is $89.6 \mathrm{~dB}$, as indicated by the solid curve in the figure, which is also the prediction of the deterministic models. The results converge well both in terms of the mean value and in terms of the significant variation range of $6 \mathrm{~dB}$, also indicated in the figure. The distribution of the simulation results is slightly asymmetrical about the mean value.

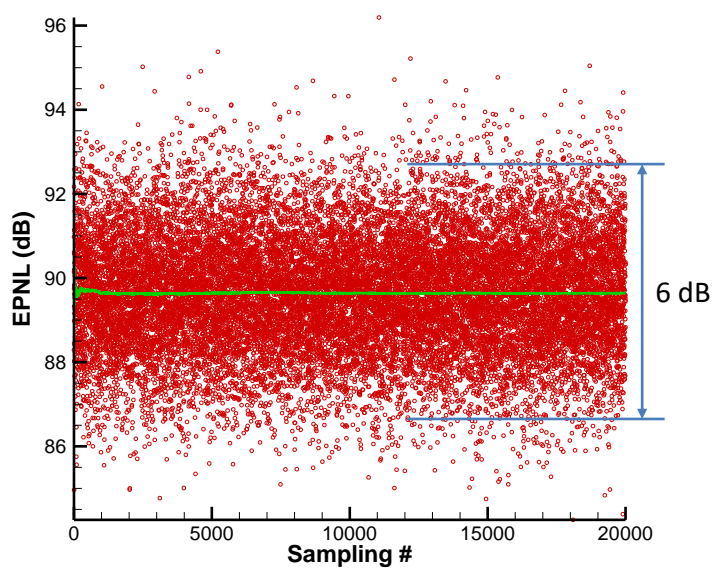

Figure 30. Results of Monte Carlo simulation.

The convergence and the distribution of the simulation results can also be clearly revealed by the sample data count histogram, which is shown in Figure 31, with each bar representing the number of samples in a bin. The histogram has an approximate normal distribution with the sample count falling off monotonically on both sides of the maximum which corresponds to the $89.6 \mathrm{~dB}$ mean value of the EPNL.

Standard statistical measures can be derived from the simulation results, of which, five are shown in Figure 32, all as a function of the sampling number. These include the standard deviation, the absolute deviation, the variance, the skewness and the kurtosis. They describe various aspects of the random data set with well-known definitions. The relatively small variations with the sampling number is another indication of the good behavior of the random data. It can be seen that both the skewness and the kurtosis are very small, meaning that the data distribution is almost symmetrical, as already shown in Figure 30 and Figure 31. Of this set of statistic measures, the standard deviation is probably the most commonly used. In the case shown in Figure 32, the standard deviation is 1.4 EPNL $\mathrm{dB}$, meaning that there is a 95\% probability that repeated predictions will stay within the range of 5.6 EPNL dB, namely, $\pm 2.8 \mathrm{EPNL} \mathrm{dB}$ around the mean value. It should be pointed out that the random variations in the predicted noise levels discussed here are due to the uncertainties in the prediction models, not because of other factors such as design deviations and operation condition variations. These other factors will also lead to variations in the noise levels. For example, it is noted that in flight tests, random variations in the aircraft operation conditions can lead to noise level variations within a range of about $2 \mathrm{EPNL} \mathrm{dB}$. This is probably the minimum variation range of any prediction models because the validation and calibration of the prediction models inevitably contains the uncertainty variations in the dataset.

The analysis of Monte Carlo simulation can also be done for individual uncertainty factors, which can reveal the ranking order of these factors in their relative importance in the noise levels. This is illustrated in Figure 33, where the standard deviations of the eight uncertainty factors listed in Table 4 are plotted, together with the results for all uncertainties, as a function of the sampling number. It is shown in the figure that the most significant contribution to the total variations comes from the spectral shape parameter, followed by the complexity factor and the component amplitude factor. The ranking order of the uncertainty factors reflects the relative contributions of various modeling aspects to the EPNL metric. It, of course, also depends on the input models for these factors. If these input models are reasonably assumed, the ranking order shown in Figure 33 then points to the direction of improvement for the prediction method. In this case, improving the accuracy of the spectral shape, the complexity factor and the component amplitude model can significantly reduce the uncertainties of the predictions. 


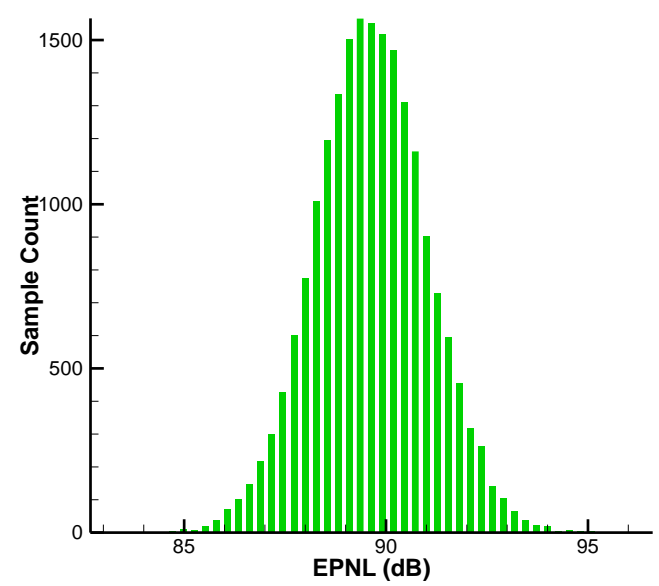

Figure 31. Sample count histogram of Monte Carlo simulation.

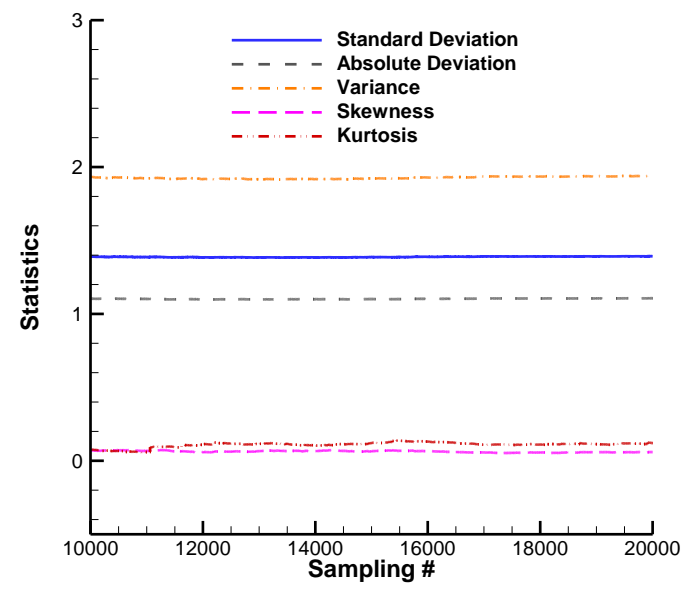

Figure 32. Statistical measures of the Monte Carlo simulation results.

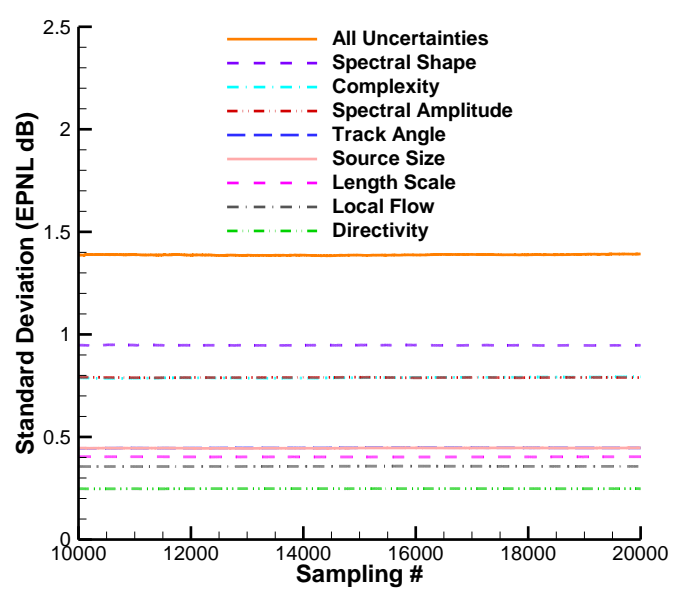

Figure 33. Ranking order of the uncertainty factors.

American Institute of Aeronautics and Astronautics 


\section{Conclusions}

An improved prediction method for aircraft landing gear noise is presented. The method builds upon and extends previously developed theory and noise modeling for full-scale isolated and installed gear assemblies. The improved capabilities and extended features make the method applicable to arbitrary sized gears in isolation or installed on conventional and unconventional airframes such as HWB aircraft. A systematic validation over a large number of datasets, covering landing gears of various sizes, designs and installations demonstrated the improvements in accuracy and robustness. This was made possible by new models that account for installation effects due to noise reflection from the airframe and deployed high-lift systems, the gear truck angle, and airframe effects on landing gear inflow velocity. In addition, the availability of both flight and wind tunnel test data allowed for improvements on Mach number and gear complexity models, so that the prediction capability is now applicable to gears of any sizes and designs. The uncertainty of the prediction method was evaluated using Monte Carlo simulations, which resulted in a 1.4 EPNL dB standard deviation. This small deviation indicates that the method can be used with confidence but assumes the input geometry and flow conditions are known. The method was implemented within NASA's system noise assessment process and used to predict the landing gear noise of future aircraft. This was the first time that a system level prediction capability was able to clearly reveal and compare the characteristics of landing gear noise for both conventional (T+W) and unconventional (HWB) aircraft designs. The availability of the new method enables and allows higher fidelity landing gear noise prediction for conceptual design assessments as well as development of landing gear noise reduction strategies.

\section{Acknowledgments}

The authors would like to thank the NASA Environmentally Responsible Aviation Project for funding this effort, Mr. John Rawls for extensive work and support to integrate the new model within ANOPP, and Mr. William Humphreys for processing and providing model-scale landing gear noise data.

\section{References}

1. Smith, M. G. and Chow, L. C. "Prediction Method for Aerodynamic Noise from Aircraft Landing Gear," AIAA98-2228. June 1998.

2. Smith, M. G. and Chow, L. C. "Validation of a Prediction Model for Aerodynamic Noise from Aircraft Landing Gear," AIAA-2002-2581. June 2002.

3. Guo, Y. P. "A Statistical Model for Landing Gear Noise Prediction," Journal of Sound and Vibration 282, pp. 61-87, 2004.

4. Guo, Y. P. "A Semi-Empirical Model for Aircraft Landing Gear Noise Prediction," AIAA Paper 2006-2627.

5. Guo, Y. P. "Effects of Local Flow Variations on Landing Gear Noise Prediction and Analysis," Journal of Aircraft 47, pp. 383-391, 2010.

6. Burley, C. L., Brooks, T. F., Humphreys, W. M. and Rawls, J. W. "ANOPP Landing Gear Noise Prediction Comparisons to Model-Scale Data," International Journal of Aeroacoustics 8(5), pp. 445-475, 2009.

7. Lopes, L. V., Brentner, K. S., Morris, P. J., Lilley, G. M. and Lockard, D. P., "Complex Landing Gear Noise Prediction Using a Simple Toolkit," AIAA Paper 2005-1202.

8. Lopes, L. V., Brentner, K. S., Morris, P. J. and Lockard, D. P., "Increased Fidelity in Prediction Methods for Landing Gear Noise," AIAA Paper 2006-2624.

9. Dobrzynski, W. M., Schning, B., Chow, L. C., Wood, C., Smith, M. and Seror, C. "Design and Testing of Low Noise Landing Gears," AIAA Paper 2005-3008.

10. Dobrzynski, W., Chow, L. C., Smith, M., Boillot, A., Dereure, O. and Molin, N. "Experimental Assessment of Low Noise Landing Gear Component Design," AIAA Paper 2009-3276.

11. Herkes, W. H., Olsen, R. F. and Uellenberg, S. "The Quiet Technology Demonstrator Program: Flight Validation of Airplane Noise-Reduction Concepts," AIAA Paper 2006-2720.

12. Ravetta, P. A., Burdisso, R. A., Ng, W. F., Khorrami, M. R. and Stoker, R. W. "Screening Of Potential Noise Control Devices At Virginia Tech For QTD II Flight Test," AIAA Paper 2007-3455.

13. Remillieux, M. C., Camargo, H. E., Ravetta, P. A., Burdisso, R. A. and Ng, W. F. "Noise Reduction of a Model-Scale Landing Gear Measured in the Virginia Tech Aeroacoustics Wind Tunnel," AIAA Paper 20082818.

14. Elkoby, R., Brusniak, L., Stoker, R. W., Khorrami, M. R., Abeysinghe, A. and Moe, J. W. "Airframe Noise Results from the QTD II Flight Test Program," AIAA Paper 2007-3457.

15. Dobrzynski, W. and Buchholz, H. "Full-Scale Noise Testing on Airbus Landing Gears in the German Dutch Wind Tunnel," AIAA Paper 97-1597. 
16. Dobrzynski, W., Chow, L.C., Guion, P. and Shiells, D. "A European Study on Landing Gear Airframe Noise Sources," AIAA Paper 2000-1971.

17. Stoker, R. W. "Landing Gear Noise Test Report," NASA Contractor Report NAS1-97040, Boeing, 1999.

18. Guo, Y. P., Yamamoto, K. J. and Stoker, R. W. "Experimental Study on Aircraft Landing Gear Noise," Journal of Aircraft 43(2), pp. 306-317, 2006.

19. Bonet, J. T., Schellenger, H. G., Rawdon, B. K., Elmer, K. R., Wakayama, S. R., Brown, D. and Guo, Y. P. "Environmentally Responsible Aviation (ERA) Project - N+2 Advanced Vehicle Concepts Study and Conceptual Design of Subscale Test Vehicle (STV)," NASA Contract Report 2013-216519, 2013.

20. Guo, Y. P., Burley, C.L. and Thomas, R. H. "On Noise Assessment for Blended Wing Body (BWB) Aircraft," AIAA Paper 2014-0365.

21. Guo, Y. P., Brusniak, L., Czech, M. and Thomas, R. H. "Hybrid Wing-Body Aircraft Slat Noise," AIAA Journal, 1-11, 10.2514/1.J052540, posted online 11 October 2013.

22. Pierce, A. D., Acoustics - An Introduction to Its Physical Principles and Applications, Mc-Graw Hill, 1981.

23. Brusniak, L., Underbrink, J. R. and Stoker, R. W. "Acoustic Imaging of Aircraft Noise Sources Using Large Aperture Phased Arrays," AIAA Paper 2006-2715.

24. Ffowcs Williams, J. E. and Hawkings, D. L. "Sound Generation by Turbulence and Surfaces in Arbitrary Motion," Phil. Tran. Roy. Soc. Lond. A264, 321, 1969.

25. Ffowcs Williams, J. E. "Hydrodynamic Noise," Ann. Rev. Fluid Mech. 1, 197-222, 1969.

26. Crighton, D. G. "Basic Principles of Aerodynamic Noise Generation," Prog. Aerospace Sci. 16(1), 31-96, 1975.

27. Humphreys, W. and Brooks, T., "Noise Spectra and Directivity for a Scale-Model Landing Gear," International Journal of Aeroacoustics 8(5), pp. 409-443, 2009.

28. Yokokawa, Y., Imamura, T., Ura, H., Kobayashi, H., Uchida, H. and Yamamoto, K. "Experimental Study on Noise Generation of a Two-Wheel Main Landing Gear," AIAA 2010-3973.

29. Stoker, R. W. and Guo, Y. P. "Airframe Noise of a Full-Scale 777 and Comparison with Past Model-Scale Tests," NASA Contract Report, Contract NAS1-97040, Task 2, February 2002.

30. Kipersztok, O. and Senguptat, G. "Flight Test of the 747-JT9D for Airframe Noise," Journal of Aircraft, Vol. 19, No. 12, December, 1982.

31. Munson, A. G. "A Modeling Approach to Nonpropulsive Noise," AIAA Paper 76-525.

32. Thomas, R. H., Burley, C. L. and Nickol, C. L. "Assessment of the Noise Reduction Potential of Advanced Subsonic Transport Concepts for NASA's Environmentally Responsible Aviation Project," accepted for the AIAA SciTech 2016 Conference, January, 2016.

33. Nickol, C. L. and Haller, W. J. "Assessment of the Performance Potential of Advanced Subsonic Transport Concepts for NASA's Environmentally Responsible Aviation Project," AIAA SciTech, January, 2016, San Diego, CA, (accepted for publication).

34. Guo, Y. P. "Empirical Prediction of Aircraft Landing Gear Noise,” NASA/CR-2005-213780, July 2005. 